\title{
III. Ideologie und Praxis der NS-Motorisierungspolitik
}

\section{Die staatliche Förderung der Motorisierung}

Reichspropagandaminister Joseph Goebbels nannte auf der Internationalen Automobil- und Motorrad-Ausstellung von 1938 das 20. Jahrhundert das "Jahrhundert des Motors" 1 . Seiner technikgeschichtlichen Interpretation fügte Goebbels in derselben Rede ein politisches Bekenntnis hinzu: „Der Nationalsozialismus ist die moderne politische Ausdrucksform des 20. Jahrhunderts." 2 Was lag näher, und darin bestand die Intention dieser Rede, als eine Verbindung zwischen einer "modernen politischen Ausdrucksform“ und der modernen Technik anzustreben. Der „Motor" steht nach diesem Verständnis nicht einfach nur für motorisierte Fortbewegung, sondern er ist selbst gewähltes Symbol für die Modernität der NS-Bewegung. Wie und warum der „Motor“ zu einem Bestandteil der nationalsozialistischen Weltanschauung und zu einem Instrument nationalsozialistischer Machtausübung wurde und inwiefern die NS-Motorisierungspolitik als "modern“ oder „antimodern“ bezeichnet werden kann, soll im folgenden Kapitel erörtert werden. Eingebettet in die Beschreibung der Ideologie (Verständnis von Technik und Motorisierung) und Praxis (Förderungsmaßnahmen) der Motorisierung im „Dritten Reich" gilt das besondere Augenmerk dem ideologischen Beitrag des Nationalsozialistischen Kraftfahrkorps in seinem Selbstverständnis als „Banner- und Willensträger" der Motorisierung.

\section{Motorisierung - die neue Zielvorgabe in der NS-Programmatik 1933: Motive und Hintergründe}

Die Nationalsozialisten traten bald nach der Machtübernahme 1933 mit dem Versprechen an die Öffentlichkeit, die Motorisierung Deutschlands mit allen Mitteln vorantreiben zu wollen. Diese Ankündigung wirft Fragen nach den Beweggründen eines solchen Vorhabens auf: Warum stellte Hitler für den „Volksgenossen“ keine öffentlichen Verkehrsmittel bereit, warum setzte er also auf den Volkswagen und nicht auf die preisgünstigere und gemeinschaftsfreundlichere Variante der Fortbewegung, z. B. auf einen „Volksomnibus“ oder die Eisenbahn? Warum förderte er das Automobil, das Anfang der dreißiger Jahre von Teilen der Bevölkerung für Luxus und Dekadenz stand und von vielen als Symbol einer ungesunden Großstadtmoderne angesehen wurde? Warum stellte sich Hitler so deutlich auf die Seite der technischen Rationalität, die von deutsch-nationalen und völkischen

RDA (Hrsg.): „Das Kraftfahrzeug. Verkehrsmittel des ganzen Volkes“, S. 7.

2 Ebenda. 
Kreisen mit ihrer Kritik gegen den industriellen Kapitalismus und die Technisierung der Gesellschaft abgelehnt wurde?

Neben diesen ideologischen Ambivalenzen gab es auch rein praktische Probleme, die von Anfang an gegen eine Volksmotorisierung sprachen. Der erhöhte Benzinbedarf für eine steigende Zahl an Kraftfahrzeugen widersprach den Autarkiezielen im „Dritten Reich“, da künstlich hergestellte Ersatztreibstoffe nicht in ausreichendem Maße zur Verfügung standen. ${ }^{3}$

Ein Blick auf die politische Ebene zeigt, dass auch die NS-Wirtschaftsprogrammatik vor 1933 nicht erkennen ließ, dass die Regierung Hitler nach der Machtübernahme so deutliche Akzente in Richtung Automobilisierung der Gesellschaft setzen würde. Adolf Hitler hatte zwar in einzelnen Wahlkampfreden am Beispiel der Automobilindustrie den Niedergang der deutschen Wirtschaft erklärt und damit gezeigt, dass er mit den Zusammenhängen von Absatzziffern, Fabrikationsmethoden und Kaufkraft in den USA und Deutschland vertraut war, doch eröffnete der Oppositionspolitiker keine politischen Lösungswege. ${ }^{4}$

Der sozialrevolutionäre Flügel der NSDAP um Gregor Straßer hielt den Autobahnbau ohnehin für verschwenderischen Luxus und sah deshalb keinen Grund, technische Großprojekte wie den Autobahnbau in den Arbeitsbeschaffungskata$\log$ aufzunehmen. ${ }^{5}$ Auch der NSDAP-Wirtschaftsexperte und Ingenieur Gottfried Feder, der die NS-Programmatik bis zur Machtübernahme mit kapitalismuskritischen Tönen versehen hatte, sah in einer Erhebung der Automobilindustrie zur Schlüsselindustrie kein Heilsversprechen.

Die NSDAP-Fraktion im bayerischen Landtag beschränkte sich 1924 bis 1933 in ihren Aussagen zur Wirtschaftspolitik auf Schuldzuweisungen an die Regierung. Die Reden der Abgeordneten behandelten an Stelle der Tagespolitik die Notwendigkeit eines politischen Systemwechsels. ${ }^{6}$ Auch die NSDAP-Reichstagsfraktion tat sich 1930 nicht mit motorisierungsfreundlichen Äußerungen hervor. Sie stellte sich im Parlament rigoros auf die Seite der Landwirtschaft und befürwortete eine weitreichende Abnahmepflicht von landwirtschaftlich erzeugtem Spiritus im Ausgleich zu Mineralölimporten, was in der Konsequenz einen weiteren Anstieg der Benzinkosten zur Folge gehabt hätte. ${ }^{7}$ Doch änderte die NSDAP bald ihren Kurs, denn der Reichsverband der Automobilindustrie (RDA) ver-

\footnotetext{
Vgl. Radkau: Technik in Deutschland, S. $308 \mathrm{ff}$.

Vgl. Weinberg (Hrsg.): Adolf Hitler. Reden, Schriften, Anordnungen, Bd. 2A, S. 84.

Vgl. Schütz u.a: Mythos RAB, S. 34.

Probst: Die NSDAP im Bayerischen Landtag 1924-1933, S. $144 \mathrm{f} ., 204 \mathrm{f}$.
}

7 Treibstoffimporteure waren verpflichtet, eine gewisse Menge an heimischem Spiritus zu beziehen („Beimischungspflicht"), die bis zu 10\% der eingeführten Treibstoffmenge entsprach. Diese Regelung war eine volkswirtschaftliche Hilfe für die Landwirtschaft im Umfang von jährlich rund 80 Millionen RM, die jedoch zu Lasten des Kraftverkehrs ging; vgl. Machemer u. a.: Nationale Treibstoffwirtschaft, S. 91; Zatsch: Allen Fehlzündungen zum Trotz, S. 177, 180. Der Antrag der NSDAP-Fraktion vom 18.10. 1930, in dem die Reichsregierung ersucht wurde, die gesetzliche Beimischungspflicht von Spiritus zu Treibstoffen auf bis zu 10\% auszudehnen und die in der Verordnung vom 4. 7. 1930 enthaltenen Beschränkungen aufzuheben, ging sogar noch über die Regierungsmaßnahmen zum Schutz der Landwirtschaft hinaus; vgl. Frick: Die Nationalsozialisten im Reichstag 1924-1931, S. 10; Döring: „Parlamentarischer Arm der Bewegung“, S. 251. 
nahm ab 1932 motorisierungsfreundlichere Signale. Der Wirtschaftsberater der NSDAP Walther Funk versprach im Juli 1932, sich den Problemen der Kraftverkehrswirtschaft anzunehmen. Gegenüber dem Vorsitzenden des RDA Robert Allmers betonte er, dass die NSDAP eine "Totallösung " anstrebe, um dem modernen Verkehrsmittel Automobil die ihm gebührende Stellung zu sichern. ${ }^{8}$ Allerdings waren im wirtschaftspolitischen Aufbauprogramm der NSDAP von 1932 weder konkrete Hinweise auf diese "Totallösung“ zu finden, noch auf die wichtige Rolle des Straßenbaus zur Arbeitsbeschaffung oder auf eine Schlüsselfunktion der Automobilindustrie. ${ }^{9}$ Die Forderung Straßers in seiner Reichstagsrede im Mai 1932, den Ausbau des Landstraßennetzes als Teil eines Arbeitsbeschaffungsprogrammes in Angriff zu nehmen, ${ }^{10}$ ging nicht über die angekündigten Maßnahmen hinaus, die der neue Reichskanzler von Papen in seinem Wirtschaftsprogramm vom September 1932 versprach. ${ }^{11}$ Es wird deutlich, dass die NSDAPParteispitze vor der Regierungsübernahme kein eigenständiges Motorisierungsprogramm entwickelt hatte. Deshalb verdienen die Gründe für die weitreichenden verkehrspolitischen Ankündigungen des neuen Reichskanzlers im Frühjahr 1933 Beachtung.

\section{Adolf Hitlers „Liebe zum Motor“}

Ein wichtiges Motiv für dieses machtvolle Bekenntnis zur Motorisierung im Frühjahr 1933 ist in der persönlichen Motorisierungsbegeisterung Hitlers zu finden. Wiederholt brachte er seine Euphorie zum Ausdruck: „Meine Liebe gehört dem Automobil. Das Auto hat mir die schönsten Stunden meines Lebens geschenkt, das muß ich wirklich sagen: Menschen, Landschaften, Denkmäler!"12 NS-Parteistatistiker verkündeten stolz, dass Hitler vom Zeitpunkt seiner Haftentlassung 1924 bis zur Machtübernahme 1933 rund anderthalb Millionen Kilometer im Auto zurückgelegt habe. ${ }^{13}$ Hitlers altbewährtes Gefolge, bestehend aus Adjutanten, den Fahrern Brückner, Schaub und Schreck und dem Fotografen

8 Vertrauliche Information des RDA-Vorsitzenden Allmers vom 16. 7. 1932, DCC-Konzernarchiv, Best. Kissel 9.20. Den Eindruck, dass sich die NSDAP der Angelegenheiten der Automobilindustrie annehmen werde, gewann der RDA auch bei einer Besprechung mit der NSDAP-Reichsleitung am 26. 8. 1932, in der sich die NSDAP für die Herabsetzung des Benzinzolls und gegen einen Spritbeimischungszwang aussprach; Vertrauliche Information des RDA-Vorsitzenden Allmers an die Mitglieder vom 31.8. 1932, ebenda.

9 Vgl. Das wirtschaftspolitische Aufbauprogramm der NSDAP (Druckschrift).

10 Vgl. Döring: "Parlamentarischer Arm der Bewegung“, S. 304 f.; RDA-Mitteilung vom 17.6. 1932 an den Vorstand, betr. Stellungnahme der nationalsozialistischen Partei zur Frage Eisenbahn-Kraftwagen, DCC-Konzernarchiv, Best. Kissel 9.20.

11 Ein wesentliches Ziel des Wirtschaftsprogramms war die Arbeitsbeschaffung und die Entlastung der Wirtschaft. Zu diesem Zweck wurde die Durchführung öffentlicher Arbeiten im Bereich des Straßen- und Wasserstraßenbaus in Gesamthöhe von 135 Millionen RM angekündigt; vgl. Streitz (Hrsg.): Quellen zur deutschen Wirtschafts- und Sozialgeschichte vom Ersten Weltkrieg bis zum Ende der Weimarer Republik, Dok. 65.

12 Hitler auf der Wolfsschanze am 9./10. 1. 1942; zit. nach Jochmann: Monologe im FührerHauptquartier 1941-1944, S. 192.

13 Motorschau vom Februar 1937: „Der Führer und die Motorisierung Deutschlands 1936“. 
Heinrich Hoffmann, wurde auch die "Chauffeureska"14 des „Führers" genannt. Mit seiner Lieblingsmarke Mercedes-Benz posierte er auf vielen Bildern vor und nach der Machtübernahme. So schien in visueller Hinsicht die Symbiose zwischen dem „Führer“ des „Dritten Reiches“ und dem aufstrebenden Unternehmen mit dem Stern perfekt.

Hitler pries das Automobil als eines der „schönsten Geschenke an die Menschheit" ${ }^{15}$ Die Arbeiter hätten durch Fleiß und Können technische Gedanken in "wahre Meisterwerke von Präzision und ästhetischer Schönheit" umgewandelt, lobte Hitler. ${ }^{16}$ Mit ähnlichen Worten, jedoch weit ekstatischer, hatte sich die künstlerische Avantgarde des italienischen Futurismus bereits zu Beginn des Jahrhunderts an der Ästhetik von Autos und Rennwagen berauscht. ${ }^{17}$ Auch Benito Mussolini, selbst ein passionierter Flieger, teilte die Motorisierungsleidenschaft Hitlers. Zum Mythos des „Duce“ gehörte seine Aufgeschlossenheit für moderne Verkehrsmittel. Zahlreiche Postkarten zeigen ihn am Steuer eines Autos, eines Flugzeugs oder am Lenker eines Motorrads. ${ }^{18}$

Angetan von Hitlers persönlichem Einsatz für die Entwicklung, Verbesserung und Verbreitung des Automobils lobten Parteipresse und Vertreter der Motorenindustrie den technischen Sachverstand des „Führers". Seine Äußerungen zu Themen der Technik und des Verkehrswesens verrieten in jedem Fall ein großes Interesse an technischen Zusammenhängen. ${ }^{19}$

Hitler erklärte seine "Liebe zum Automobil“ nicht nur mit seinem Respekt vor dem Wunderwerk der Technik und dem großen praktischen Nutzen. Dem Auto sei es zu verdanken, so seine philosophische Einlassung, dass dem Menschen die Unabhängigkeit wieder zurückgegeben werde, die ihm durch die Eisenbahn genommen war. Der Schienen- und Fahrplangebundenheit der Eisenbahn setzte Hitler in seinen Reden die "individuelle Freiheit" des Autofahrens entgegen.20 Kraftfahren steht für die Möglichkeit zur ungebundenen und individuellen Zirkulation - Vorzüge, die unabhängig von Kulturen, Zeiten und politischen Systemen in Bezug auf Kraftfahrzeuge und Flugzeuge genannt werden. ${ }^{21}$ Doch nahm Hitler mit dem "Individualismus" ein Wesensmerkmal des Liberalismus in Anspruch, und dies war - gemessen an Hitlers Diktion - durchaus ein ungewöhnliches Argument. Die Freisetzung von Individualität stand in klarem Widerspruch zu dem politischen Sozialisationsziel des Regimes: Schaffung einer gleich gerichteten "Volksgemeinschaft“. Durch eine gleichförmige Entwicklung, durch körperliche

14 Dies berichtet der enge Freund von Hitler, Ernst Franz Hanfstaengel; vgl. Kershaw: Hitler 1889-1936, S. 613.

15 Motorwelt vom 17. 5. 1935: „Tagung der AIACR in Berlin“.

16 RDA (Hrsg.): „Kraftfahrt tut not!“, S. 11.

17 Ziegenfusz: Il Futurismo, S. $35 \mathrm{f}$.

18 Zur Selbstdarstellung des Faschismus in Italien vgl. Falasca-Zamponi: Fascist spectacle, S. 70.

19 Hitler war technikinteressiert, jedoch nicht immer fachkundig, wie an entwicklungstechnischen Fehlentscheidungen im Krieg erkennbar war; vgl. Zitelmann: Hitler, S. 362; Faulenbach: Zur Einleitung in das Themenfeld "Technik und Arbeit“, S. 79.

20 Vgl. RDA (Hrsg.): „Kraftfahrt tut not!“, S. 7.

21 Vgl. Behringer u. a.: Der Traum vom Fliegen, S. 485. 
Ertüchtigung und weltanschauliche Schulung sollte sich der Einzelne in einen "gleichgeschalteten“, angepassten und gehorsamen „Volksgenossen“ verwandeln. ${ }^{22}$ Sich selbst zu entscheiden, wohin, wann und wie schnell man fährt, symbolisierte ein $\mathrm{Ma} ß$ an Freizügigkeit und Autonomie, das in anderen Freizeitbereichen aufgrund der Einbindung in Gemeinschaftsrituale nicht zugelassen wurde.23 In einem nach totalitärer Herrschaftsausübung strebenden Staat, in dem auch die private Sphäre vor dem öffentlichen Zugriff nicht geschützt war, stellte der motorisierte Individualverkehr einen Freiraum dar. Das Image des Autos als Freiheitssymbol wurde im „Dritten Reich“ nicht gebrochen, sondern im Gegenteil durch die staatlich geförderte Wertschätzung des Motorsports noch erhöht.

Ein weiterer Grund, warum die Nationalsozialisten die Eigenschaftswörter „individuell“ und „freizügig“ im automobilen Kontext mit positiven Konnotationen belegten, ist einem politischen Abgrenzungsbestreben zuzuschreiben. Der Staatssekretär im Reichspropagandaministerium Wilfried Bade bezeichnete die Personenbeförderung mit der Bahn als "kollektivistische Zwangsbeförderung “. ${ }^{24}$ Die sich darin ausdrückende Abneigung gegen den "Massenverkehr" war eine verdeckte Verbalattacke gegen den Sozialismus und Kommunismus. Antikollektivistische Anklänge hatte auch Hitlers Eröffnungsrede auf der IAMA von 1936, in der er ausführte, dass die Förderung der Motorisierung abhängig sei von der „vollen Freizügigkeit eines Volkes, sich ihrer zu bedienen, und zwar nicht nur von der gesetzlichen, sondern vor allem auch von der psychologischen Freizügigkeit" ${ }^{\text {“ }} .{ }^{25}$ Hitler fügte hinzu, es sei kein Zufall, dass es nur einen niedrigen Prozentsatz an Kraftfahrzeugen im „bolschewistischen“ Russland gebe.

$\mathrm{Da}$ die Motorisierung des Verkehrswesens in der Sowjetunion erst ab 1928 planmäßig einsetzte, lag sie im Motorisierungsvergleich mit den USA und Europa tatsächlich weit zurück. ${ }^{26}$ Nationalsozialisten, die für diesen Rückstand eine kulturelle Rückschrittlichkeit und das kommunistische Herrschaftssystem verantwortlich machten, versuchten, das NS-Regime im Verkehrsbereich als freiheitsliebend, freizügig und menschenfreundlich in Szene zu setzen.

Hitler begründete seine persönliche Vorliebe für die individuelle motorisierte Fortbewegung auf der Automobilausstellung 1933 auch mit der sich bietenden Kontrollmöglichkeit über mechanische Kräfte: „Nicht der Fahrplan, sondern der

22 Vgl. Janka: Die braune Gesellschaft, S. 253, 370.

23 Die KdF-Organisation war bestrebt, das private Reisen zu vergemeinschaften; ebenda, S. $379 \mathrm{ff}$.

24 Bade: Das Auto erobert die Welt, S. 311. Bereits Otto Julius Bierbaum, der als einer der ersten Literaten 1903 eine Hommage an das Auto verfasste, verglich die Eisenbahn mit einem "Gefängnis“; ders.: Eine empfindsame Reise im Automobil, S. 269.

25 RDA (Hrsg.): "Schrittmacher der Wirtschaft", S. 12.

26 Im Rahmen des ersten Fünfjahresplans (1928-1933) wurden drei Automobil-Großfabriken in Moskau angelegt. Probleme ergaben sich durch die mangelhafte Treibstoffverteilung und die Uneinheitlichkeit der Besitzverhältnisse. Außerdem gelang es trotz der Anstrengungen noch nicht, Gütertransporte im Lkw-Verkehr über größere Entfernungen einzurichten. Der zweite Fünfjahresplan (1933-1937) sah auf dem Gebiet des Verkehrswesens eine beträchtliche Steigerung der Automobilproduktion sowie eine Intensivierung des Verkehrs vor. Für die dritte Periode (1938-1942) plante man eine weitere Erhöhung; Haudan: Das Motorisierungspotential der Sowjetunion, S. $21 \mathrm{ff} ., 60 \mathrm{f}$. 
Wille des Menschen bedient sich des ihm ununterbrochen gehorchenden Verkehrsinstrumentes."27 Die Möglichkeit, ein motorgetriebenes Fahrzeug zu führen, stellte den vermeintlich nächsten Schritt zu einer souveränen Beherrschung von Raum und Zeit dar. ${ }^{28}$ Hitler gab damit auf die umstrittene Frage nach der Steuerbarkeit technischer Systeme eine technikoptimistische Antwort, die einen Kontrapunkt zu vielen intellektuellen Bedenkenträgern der Weimarer Republik setzte. Oswald Spengler etwa hatte die Sorge über eine Verselbständigung technischer Rationalität in seinem Buch „Der Mensch und die Technik“ 1931 auf den Punkt gebracht: „Der Herr der Welt wird zum Sklaven der Maschine.“29 Die Utopie von der absoluten Beherrschbarkeit der Technik und die daraus resultierenden Allmachtsphantasien waren ein nicht zu unterschätzendes Antriebsmoment nationalsozialistischer Technikbegeisterung.

Hitlers Einsatz für die Motorisierung rührte nicht nur aus persönlichen Neigungen und Vorlieben, sondern gründete sich auf ihrem großen wirtschaftlichen, militärischen und propagandistischen Potenzial, das für die Erreichung nationalsozialistischer Herrschaftsziele nützlich war. $\mathrm{Zu}$ den wirtschaftlichen Gründen zählten die Arbeitsbeschaffung, mögliche Deviseneinnahmen, die Belebung zahlreicher Neben-Industriezweige und die Ankurbelung des Konsums. Hitler erklärte die Förderung der Motorisierung mit dem volkswirtschaftlichen Ziel, hunderttausende Menschen in Lohn und Brot zu bringen und durch die Kaufkraftsteigerung „immer größeren Massen unseres Volkes die Gelegenheit zu bieten, dieses modernste Verkehrsmittel zu erwerben " ${ }^{30}$ Adolf Hitler, der große Bewunderer des amerikanischen Autobauers Henry Ford, appellierte an die Automobilindustrie, ihre Produkte durch standardisierte Massenfertigung und sinkende Preise für jedermann erschwinglich zu machen. Die Ankündigung einer nationalen Motorisierung stand für ein Glücksversprechen der NS-Regierung an den motorisierungswilligen "Volksgenossen“ und für die Aussicht auf einen baldigen wirtschaftlichen Aufschwung.

Auch militärische Motive gaben für Hitler den Ausschlag, die Motorisierung des Verkehrs in Angriff zu nehmen. Als wesentliche Erkenntnis aus dem Ersten Weltkrieg hatte sich bei Hitler die Überzeugung durchgesetzt, dass in dem kommenden technischen Krieg die allgemeine Motorisierung kampfbestimmend sein würde. ${ }^{31}$ Umgerechnet auf die Bevölkerungszahl lag Deutschlands Bestand an Kraftfahrzeugen 1930 im Vergleich zum potenziellen Gegner Frankreich im Verhältnis 1:3 zurück. ${ }^{32}$ In „Mein Kampf“ führte Hitler mit Besorgnis aus: „Der allgemeinen Motorisierung der Welt, die im nächsten Krieg schon in überwältigen-

27 RDA (Hrsg.): „Kraftfahrt tut not!“, S. 8. Hitler strebte in der Praxis aber keineswegs die Ablösung der Eisenbahn an. Vgl. auch seine Pläne für eine transkontinentale Großraumeisenbahn; Joachimsthaler: Die Breitspurbahn Hitlers.

28 Diesen Zusammenhang stellte das Nachwort zu der Neuausgabe der 1925 erschienenen Autobiografie von Carl Benz her; vgl. ders.: Lebensfahrt eines deutschen Erfinders, S. $153 \mathrm{f}$.

29 Spengler: Der Mensch und die Technik, S. 75.

30 RDA (Hrsg.): „Vollgas voraus!“, S. 11.

31 Vgl. Hitler: Mein Kampf, 2. Bd. S. 748.

32 Vgl. Ludwig: Technik und Ingenieure im Dritten Reich, S. 310. 
der Weise kampfbestimmend in Erscheinung treten wird, könnte von uns fast nichts entgegengestellt werden." ${ }^{33}$ Eine breit angelegte Motorisierung sollte Mobilitätsdefizite und Transportprobleme beseitigen. Des Weiteren setzte sich Hitler gegen den Willen einiger Fachmilitärs für den Aufbau einer eigenständigen Panzerdivision als Angriffsverband ein. ${ }^{34}$

\section{Die NSDAP zwischen Technikskepsis und Technikbegeisterung}

Einige hochrangige NS-Führer zeigten eine ähnliche Technikbegeisterung wie Hitler oder waren der Technik gegenüber zumindest aufgeschlossen. Bei aller Unterschiedlichkeit des persönlichen und beruflichen Werdegangs hatten viele NSFunktionäre einen persönlichen Bezug zur Motorisierung: Obgleich der Reichsführer SS Heinrich Himmler, ein gelernter Diplomlandwirt, mystizistische und altgermanische Riten innerhalb der SS einführte, war er doch kein Gegner moderner Technik. Er fuhr als Funktionär im Reichstagswahlkampf 1924 mit seinem Motorrad niederbayerische Dörfer ab und war wie auch der Reichspressechef der NSDAP Otto Dietrich Mitglied im Deutschen Touring Club. ${ }^{35}$ Außerdem ließ Himmler ein außerordentlich starkes Interesse am Grand-Prix-Rennsport erkennen. ${ }^{36}$ Der SS-Obergruppenführer Erich von dem Bach-Zelewski arbeitete zwischenzeitlich als Taxifahrer. ${ }^{37}$ SS-Obergruppenführer Philipp Bouhler, der Chef der Kanzlei des Führers, und der General der Landespolizei, Ministerialdirektor Daluege, nahmen aktiv an Motorsportveranstaltungen teil. ${ }^{38}$ Martin Bormann, der spätere Leiter der Parteikanzlei, hatte die Gründung des NS-Automobilkorps (NSAK) initiiert. SA-Obergruppenführer Adolf Hühnlein repräsentierte als Inspekteur der SA- und SS-Motorstürme und als stellvertretender Korpsführer des NSKK vor der Machtübernahme den „Motorisierungswillen“ der Partei. Der Architekt Albert Speer trat 1931 nicht nur in die NSDAP ein, sondern wurde auch Mitglied des neu gegründeten NSKK. Er erledigte für die Berliner Kreisleitung Kurierfahrten. ${ }^{39}$ Auch Hermann Göring hatte, als erfolgreicher Jagdflieger im Ersten Weltkrieg und als Reichsminister für Luftfahrt, eine besonders enge Beziehung zur Motorisierung. Eine demonstrative Technikfreundlichkeit legte der zwischen 1933 und 1937 amtierende Reichsverkehrsminister Paul von Eltz-Rübenach ${ }^{40}$ an

33 Hitler: Mein Kampf, 2. Bd., S. 748.

34 Vgl. Zimmermann: Die Rolle der Technik im Zweiten Weltkrieg, S. 402.

35 Vgl. Höhne: Der Orden unter dem Totenkopf, S. 39, 43. Die genannten Namen werden in den Presseerzeugnissen des DTC aufgeführt; vgl. Der Motor-Tourist vom 15. 8. 1933 und Clubnachrichten des DTC vom 15. 3. 1933.

$36 \mathrm{Vgl}$. dazu auch S. 296 dieser Arbeit.

37 Vgl. Weiß (Hrsg.): Biographisches Lexikon, S. $25 \mathrm{f}$.

38 Vgl. Otte: Kraftwagensport, S. 113.

39 Vgl. Speer: Erinnerungen, S. $35 \mathrm{ff}$.

40 Reichspost- und Verkehrsminister Paul von Eltz-Rübenach schied Anfang 1937 aus dem Amt. Sein Nachfolger wurde der Generaldirektor der Deutschen Reichsbahngesellschaft Julius Dorpmüller. Eigenständiger Postminister wurde im Februar 1937 Wilhelm Ohnesorge; vgl. Gottwaldt: „Fahren für Deutschlands Sieg!“, S. 164, 182. 
den Tag, der die Technik und mit ihr die Motorisierung als kulturelle Errungenschaften pries. ${ }^{41}$

Doch die technikoptimistische Haltung war nicht auf allen Ebenen und in allen Flügeln der NSDAP gleich stark ausgeprägt oder vertreten. Innerhalb der NSDAP-Führungsschicht beispielsweise war die Gruppe der technischen Intelligenz mit Fritz Todt, Gottfried Feder, Albert Speer und Xaver Dorsch unterrepräsentiert. ${ }^{42}$ Außerdem gab es namhafte Persönlichkeiten in der NSDAP, bei denen zu vermuten war, dass sie Vorbehalte gegen ein so weitreichendes Motorisierungsvorhaben hegen würden. $\mathrm{Zu}$ den pateiinternen Kritikern ist der sozialrevolutionäre und mittelständisch orientierte Flügel um Gregor Straßer zu zählen, der aus Gegnerschaft zur Großindustrie und aus Abneigung gegen das Luxusgut Auto einer Förderung der Automobilindustrie und des Autobahnbaus ablehnend gegenüber stand. Zu nennen sind aber auch die „Blut- und Boden-Ideologen“ wie z. B. Reichsbauernführer Walther Darré und Alfred Rosenberg, die Agrarutopien gegenüber aufgeschlossen waren und den Sturz der bürgerlich-kapitalistischen Herrschaft anstrebten. ${ }^{43}$

Doch zum einen waren Technikskeptiker wie Darré keine Fundamentalkritiker, wie seine Rede auf dem Reichsbauerntag 1937 in Goslar zeigt, in der er die Notwendigkeit der Motorisierung der Landwirtschaft unterstrich. ${ }^{44}$ Zum anderen zählten die Skeptiker nicht zu den einflussreichsten Politikern im „Dritten Reich“. Entscheidend für den technikfreundlichen Kurs der Regierung waren die Reden und Verlautbarungen von Hitler, Goebbels und Göring, die auf die Möglichkeiten der Technik setzten und einer Verbindung der völkischen Ideologie mit der modernen Technik das Wort redeten.

\section{Kernpunkte des NS-Motorisierungsprogramms}

Als erster Reichskanzler in der Geschichte der Automobilausstellungen eröffnete Adolf Hitler am 11. Februar 1933 die Internationale Automobil- und MotorradAusstellung. Er kündigte ein Bündel von Einzelmaßnahmen zur Förderung der Motorisierung an, das von der NS-Propaganda zu einem von Hitler konzipierten "Motorisierungsprogramm" stilisiert wurde. Hitler formulierte vier Ziele, die seine Regierung in Angriff nehmen wollte: 1 . Herausnahme der staatlichen Interessenvertretung des Kraftwagenverkehrs aus dem Rahmen des bisherigen Verkehrs; 2. Steuerliche Entlastung; 3. Durchführung eines großzügigen Straßenbauplanes und 4. Förderung sportlicher Veranstaltungen. ${ }^{45}$

41 Vgl. von Eltz-Rübenach auf dem Begrüßungsabend des RDA am 18. 2. 1936, in: RDA (Hrsg.): „Schrittmacher der Wirtschaft“, S. 31.

42 Vgl. Sang: Technik und Staat, S. 137.

43 Sobald jedoch "blindwütig“" und von der falschen Seite Kritik an der Technik geübt wurde, nahm auch Rosenberg sie in Schutz, indem er „ihr Hervortreten auf einen ewigen germanischen Antrieb“ zurückführte; Rosenberg: Mythus des 20. Jahrhunderts, S. $142 \mathrm{f}$.

44 Ziel war es, eine jährliche Produktionsziffer von 50000 landwirtschaftlichen Zugmaschinen zu erreichen; Krafthand vom 25. 2. 1939: „Reichsinnungsmeister Pg. Stupp eröffnet die 4. Reichstagung des Kraftfahrzeughandwerks“.

45 RDA (Hrsg.): „Kraftfahrt tut not!“, S. 10. 
Hitler griff damit wesentliche Forderungen der Automobillobby an die Regierungen der Weimarer Republik in den Bereichen Steuern und Straßenbau auf.46 Die Hoffnungen der Wirtschaft und der Autofahrerverbände auf staatliche Förderung des Individualverkehrs schienen sich durch die Ankündigungen Hitlers auf der IAMA und die Aufwertung des Kraftfahrsektors im Reichsverkehrsministerium zu erfüllen. Die Herausnahme der staatlichen Interessenvertretung des Kraftwagenverkehrs aus dem Rahmen des bisherigen Verkehrs wurde durch die Bestellung eines eigenen Ministerialdirektors für die Kraftfahrt, die bisher durch den Minister für Binnenschifffahrt vertreten war, verwirklicht. ${ }^{47}$

Auch die schwierige Situation der privaten Kraftfahrer - im Sommer 1932 waren $28 \%$ der $\mathrm{Pkw}$ und $43,5 \%$ der steuerpflichtigen Motorräder vorübergehend abgemeldet - schien sich zu verbessern. ${ }^{48}$ Als Impulsgeber für Neukunden diente das neue Kraftfahrzeugsteuergesetz vom 11. April 1933, das alle erstmals zum Verkehr zugelassenen Motorräder und Autos unbesteuert ließ; außerdem wurde ab 31. Mai 1933 den Besitzern von Altwagen die Möglichkeit geboten, die auf dem Fahrzeug lastende Steuer durch Entrichtung eines einmaligen Betrages abzulösen. ${ }^{49}$ Im Ergebnis war Ende 1933 ein Drittel des gesamten Pkw-Bestandes steuerfrei. 50

Doch die Fördermaßnahmen wurden von der Bevölkerung nicht nur positiv aufgenommen. Die hohen Unterhaltskosten blieben auch nach dem Inkrafttreten des neuen Kraftfahrzeugsteuergesetzes bestehen und erregten zusammen mit den Steuererleichterungen für Neuwagen den Unmut von Altwagenbesitzern. Der Lagebericht der Gestapo Berlin-Brandenburg vom Juli 1934 gab die Meinung der Unzufriedenen wieder: „Fast alle Dienststellen der NSDAP hätten nach wie vor nagelneue teuere Autos, die das Volk bezahlen müsse. Diese Autos führen alle steuerfrei, während der arbeitende Volksgenosse immer noch die viel zu hohen Steuern für Altwagen aufbringen müsse. "51

Ein wesentliches Ziel der Motorisierungspolitik bestand in dem Bestreben, die Abhängigkeit Deutschlands von Mineralölzufuhren aus dem Ausland zu verringern. Der Benzinvertrag, der am 14. Dezember 1933 zwischen der IG Farben AG

$46 \mathrm{Vgl}$. das Grundsatzprogramm zur Motorisierung, Eingabe des RDA vom 16. 8. 1932 an den neuen Kanzler von Papen, abgedruckt in Roth: Der Weg zum guten Stern des „Dritten Reichs“, S. 108 f.; Vgl. auch die Forderungen der Automobilindustrie von 1928, in: Das deutsche Automobilwesen der Gegenwart (Druckschrift).

$47 \mathrm{Vgl}$. Auto. Mitteilungsblatt des Gaues 3a (Hessen) des ADAC vom 1. 5. 1933: „Kraftfahrt macht frei“. Doch im Gegensatz zu Ankündigungen wurde keine einheitliche Behörde für Kraftverkehr z.B. ein „Reichskommissariat für Kraftfahrwesen“ geschaffen. Der Kraftverkehr blieb dem Reichsverkehrsministerium unterstellt; vgl. Kopper: Modernität oder Scheinmodernität?, S. 406; Zeitungsausschnitt vom 9. 3. 1933: „Vorläufig kein besonderes Reichskommissariat für Kraftfahrwesen“, BArch R 43 I/1074.

48 Vgl. Edelmann: Vom Luxusgut, S. 132.

49 Goebbels zählte die Maßnahmen in seiner Rede anlässlich der IAMA 1937 auf, vgl. RDA (Hrsg.): „Kraft des Motors, Kraft des Volkes“, S. 8.

$50 \mathrm{Vgl}$. Edelmann: Vom Luxusgut, S. 160.

51 Lagebericht der Staatspolizeistelle Potsdam für Juli 1934, in: Ribbe (Hrsg.): Die Lageberichte der Geheimen Staatspolizei, Dok. 33, S. 160f. Siehe auch den Lagebericht der Gestapo für Brandenburg für März 1934, in: ebenda, Dok. 21, S. 110. 
und der Reichsregierung abgeschlossen wurde, sah den Ausbau der synthetischen Produktion von Benzin aus Braunkohle in Leuna gegen eine staatliche Preis- und Absatzgarantie vor. ${ }^{52}$ Hätte das Motorisierungsniveau im Jahre 1937 den Stand von 1934 gehalten, wäre Deutschland in der Lage gewesen, den Bedarf an leichten Treibstoffen (Benzin, Benzol) zu etwa 90\% aus eigener Produktion zu decken. Doch infolge der Zunahme des zivilen und militärischen Bedarfs an Mineralöl reichte die Produktionssteigerung nicht aus, um das Autarkieziel auch nur annähernd zu erreichen. ${ }^{53}$ Die kostspielige Herstellungsweise von synthetischen Treibstoffen und die Entscheidung für eine weitere Erhöhung der Zollsätze für Benzin und Benzol ab dem 1. Dezember 1936 waren gegen eine Verbreiterung der Käuferschicht gerichtet, da der Unterhalt für potenzielle Neukunden unerschwinglich blieb. ${ }^{54}$

\section{Reichsautobahnen - „Straßen in die große deutsche Zukunft“55}

Ein Kernstück der Motorisierungsmaßnahmen des Regimes war der Autobahnbau. Das Gesetz vom 27. Juni 1933 über die Schaffung eines Unternehmens Reichsautobahnen knüpfte an Pläne der 1926 gegründeten HAFRABA (Verein zur Vorbereitung der Autostraße Hansestädte-Frankfurt-Basel) an. ${ }^{56}$ Die Denkschrift des Straßenbauingenieurs Fritz Todt, die Hitler zu Beginn des Jahres 1933 studierte, hatte ihn für den Autobahnbau eingenommen.

Unter ökonomischen Gesichtspunkten war das Autobahnprojekt eine Maßnahme zur Arbeitsbeschaffung. 1936 wurde ein Beschäftigungshöchststand mit 124483 Autobahnarbeitern erreicht. ${ }^{57}$ Insgesamt wurden rund eine Million Arbeitsplätze im Straßenbau und in der Automobilindustrie geschaffen. Als Arbeitsbeschaffungsmaßnahme verlor der Straßenbau ab 1936 an Gewicht, da die forcierte Aufrüstung im Rahmen des Vierjahresplans eine stärkere Auslastung der Industrie mit sich brachte. Innerhalb der Grenzen Deutschlands von 1937 waren

52 Vgl. Herbst: Das nationalsozialistische Deutschland, S. 164. Die Benzinerzeugung aus heimischen Kraftstoffen wurde ab 1936 mit der Eröffnung von Hydrierwerken bedeutsam. Die Herstellung von synthetischem Benzin basierte auf dem Bergius-Pier-Verfahren (Hochdruck-Hydrierung) und dem Fischer-Tropsch-Verfahren (Benzinsynthese); vgl. Giere: Kraftstoffe für Automobilmotoren, S. 315.

53 Vgl. Herbst: Das nationalsozialistische Deutschland, S. 165. Zur Treibstoffpolitik zwischen 1933 und 1945 vgl. auch Krammer: Fueling the Third Reich.

54 Aus der Sicht der Unternehmen war die Produktionsausweitung von den zugeteilten Rohstoff- und Materialkontingenten abhängig. Umso mehr, als Anfang 1937 die Eisenund Stahlbewirtschaftung auf Betreiben der Rüstungs- und Bauindustrie für die Automobilindustrie eingeführt wurde; Edelmann: Vom Luxusgut, S. $193 \mathrm{f}$.

55 So nannte Adolf Hitler die Autobahnen auf der IAMA 1939; vgl. Deutsche Kraftfahrt vom März 1939: „Die größte Autoschau der Welt“.

56 Weder Hitler noch Todt hatten die Autobahn "erfunden“, wie es die NS-Propaganda glauben machen wollte. Der Bau der Berliner AVUS 1912, die Inbetriebnahme einer Autobahn in Italien 1924, die Eröffnung der Autobahn Köln-Bonn 1932 und der Ausbau eines ganzen "Highway"-Systems in den USA waren Vorläufer der in Deutschland geplanten Überland-Schnellstraßen; Braun: Anfänge der Massenmotorisierung, S. 125.

57 Vgl. Gottwaldt: Julius Dorpmüller, die Reichsbahn und die Autobahn, S. 46. 
14000 Kilometer Reichsautobahnen geplant, 3860 Kilometer wurden bis zur kriegsbedingten Einstellung der Bautätigkeit im Sommer 1942 fertig gestellt.

Der zum "Generalinspektor für das deutsche Straßenwesen“ ernannte Ingenieur Fritz Todt legte sein besonderes Augenmerk beim Bau der Straßen auf ästhetische Gesichtspunkte: „Wir werden dafür sorgen, daß die Reichsautobahnen nicht nur die schnellsten, sichersten und modernsten, sondern auch die schönsten Straßen der Welt werden. " 58 "Schön" hieß bei Todt, die Autobahnen in die Landschaft einzupassen, sanfte Schwingungen und möglichst keine geraden Strecken ins Bild zu bringen und die Straßenführung so zu legen, dass dem Autofahrer die landschaftlichen Reize erschlossen werden können. ${ }^{59}$ Die Aufgabe der Technik sah Todt darin, „sich nicht nur vom rein technischen Zweck leiten zu lassen, sondern der technischen Form einen geistigen Inhalt zu geben".60 Ähnlich wie der Ingenieur sollte auch der Autobahnbenutzer an eine immaterielle Sinnschicht der Betonbahnen glauben. Die Straßen sollten dem „Volksgenossen“ das Gefühl vermitteln, eingepasst zu werden ,in die beseligende Einheit der Natur, die den Menschen empfängt, der ihr entlaufen war in die Hast und Künstlichkeit der Städte, wie einen endlich zur Mutter heimkehrenden Sohn" ${ }^{61}$ Die vorgetragene Auffassung stilisierte das Auto Fahren zum gesteigerten Naturerlebnis.

Auch im Motorgeländesport wurde eine besondere Nähe zwischen Natur und Technik konstruiert. Dem Wunschdenken der NSKK-Organisatoren gemäß würde dadurch nicht die Natur zerstört, sondern "das Verwachsenwerden des deutschen Menschen mit dem deutschen Boden gepflegt “ ${ }^{6} .62$

Die Schriftsteller und Dichter, die Oden an die Autobahn verfassten, die Autobahnmaler und die Landschaftsanwälte übertrafen sich gegenseitig an pathetischer Ehrerbietung und brachten eine große gesellschaftliche Sehnsucht nach einer Versöhnung zwischen Technik und Natur zum Ausdruck. Aufgrund der kulturellen Überhöhung der Autobahnen und ihrer öffentlichkeitswirksamen Inszenierung in den Wochenschauen, im Rundfunk, in der Malerei und in der Literatur nahmen die Autobahnen als "Straßen des Führers" in der Erinnerung der Zeitgenossen einen wichtigen Platz ein, der bis heute im kollektiven Gedächtnis der deutschen Bevölkerung verankert ist. ${ }^{63}$

Hitler setzte sich und dem „Dritten Reich“ bereits zu Lebzeiten ein Denkmal von hohem repräsentativem Wert. Kaum eine gute Eigenschaft wurde ausgelassen, wenn es um die Beschreibung der Vorteile und Schönheiten der Reichsautobahnen ging. So sollte das Ausland in den Straßen Hitlers seinen Willen zum Frieden

58 Todt: Reichsautobahnen - ein Symbol, S. 54.

59 Die Autobahn und die "Reichsautobahn“ vom 1.2. 1934: „Nationalsozialismus der Tat: Schaffung eines deutschen Volkskraftwagens" von Erwin Gottschalk.

60 Todt: Reichsautobahnen - ein Symbol, S. 53.

61 Bade: Das Auto erobert die Welt, S. 325.

62 NSKK-Obertruppführer Söldner: Geländesport - Hohe Schule der Kraftfahrt, (Buchartikel o.O., [1938]), BArch NS 24/91; NSKK-Motorbrigade Sachsen: Kraftfahrsport, S. $13 \mathrm{f}$.

63 Zur medialen Inszenierung vgl. besonders Schütz u. a.: Mythos RAB, S. 104-121; Schütz: "Jene blaßgrauen Bänder", S. 76-120. 
erkennen. ${ }^{64}$ Die Autobahnen wurden zum nationalen Symbol deutscher Einigkeit und Größe stilisiert. Das deutsche Monatsbuch „Volk und Welt“ schrieb 1935 unter der Überschrift „Vom Saumpfad zur Autobahn“:

„Fremde werden uns darum beneiden und ihrer Heimat die Kunde bringen, daß Deutschland seine Einigkeit mit steinernen Linien in das Land geschrieben hat, daß wir ein unüberwindliches Volk geworden sind, ein Volk von Straßenbauern und Überwindern der Höhen und Tiefen unseres Geschicks." ${ }^{65}$

Die Möglichkeit, auf Überlandstraßen Gaugrenzen zu überwinden und den Gegensatz zwischen Stadt und Land im Vorüberfahren aufzuheben, sprach das vom Nationalsozialismus geförderte „organische Denken“ an.66 Dies drückt sich auch in der Bezeichnung „Verkehrsdurchblutung des deutschen Raumes "67 aus. Ungeachtet dieser gefühlsbetonten Einheitsrhetorik darf die Bedeutung für die Infrastruktur nicht sehr hoch eingeschätzt werden. Das geringe Verkehrsaufkommen und die Streckenführungen ließen eine nur geringe Raumerschließungswirkung erwarten. ${ }^{68}$

Der militärische Wert der Autobahnen wird in der historischen Forschung inzwischen ebenfalls als gering veranschlagt. Die hohen Militärbefehlshaber standen dem Autobahnbau reserviert gegenüber. Zum Transport von Truppenverbänden, von großen Mengen an Material und Betriebsstoffen favorisierten sie die Eisenbahn, nicht die aus der Luft so leicht zu identifizierenden Autobahnen. ${ }^{6} 9$

Ungeachtet des geringen militärischen Nutzens hatten die Autobahnen im militärischen Kontext einen gewissen Symbolcharakter. Im Vorfeld der von Deutschland ausgelösten politischen Krisen mit der Tschechoslowakei und Polen und der darauf folgenden Annexion dieser Staaten wurden Straßenbaupläne diskutiert. Hitler setzte seine Forderungen nach Verbindungsstraßen zu den deutschen Gebieten als außenpolitisches Druckmittel ein. Die Zusage des tschechoslowakischen Staates hinsichtlich einer exterritorialen Autobahn durch sein Gebiet im Winter 1938 änderte jedoch genauso wenig an den beschlossenen Einmarschplänen der Nationalsozialisten wie die Ablehnung Polens, im Frühjahr 1939 einer Autoverbindung durch den polnischen Korridor zuzustimmen. ${ }^{70}$

${ }^{64}$ Vgl. dazu: Rede des Herrn Reichsministers Rudolf Heß anläßlich des VII. internationalen Straßenkongresses in München am 3. September 1934 (Druckschrift), S. 9. Dieses Ziel wurde zumindest bei Deutschland-Besuchern erreicht, die in den Autobahnen ein gutes und völkerverbindendes Element sahen. Britische Touristen waren von der Modernität der Straßen und der ästhetischen Streckenführung zumeist angetan; vgl. Schwarz: Die Reise ins Dritte Reich, S. $217 \mathrm{ff}$.

65 Wörner: Vom Saumpfad zur Autobahn, S. 46.

66 Vgl. die Ausführungen von Straßenbaurat Niemeyer in der Verkehrstechnischen Woche vom 5. 12. 1934: „Die Auswirkung des motorisierten Verkehrs auf Städtebau und Landesplanung“, S. 711. Darin heißt es, Wirtschaftsräume sollten zu einheitlichen organischen Gebieten zusammenwachsen, damit der „unglückliche Gegensatz zwischen Stadt und Land immer mehr beseitigt werden" könne.

67 Lengercke: Kraftfahrzeug und Staat, S. 40.

$68 \mathrm{Vgl}$. Kopper: Modernität oder Scheinmodernität?, S. $47 \mathrm{ff}$.

69 Vgl. Sang: Technik und Staat im Dritten Reich, S. $158 \mathrm{f}$.

70 Vgl. das Gespräch des deutschen Außenministers von Ribbentrop mit dem polnischen Botschafter Lipski am 21. 3. 1939; Domarus: Hitler, Bd. 2.1, S. 1107 f. und die Rede Hit- 


\section{Das Volkswagen-Projekt}

An die Motorisierung des Verkehrs knüpfte Hitler das Versprechen, „immer größeren Massen unseres Volkes die Gelegenheit zu bieten, dieses modernste Verkehrsmittel [das Auto] zu erwerben" ${ }^{71}$ Nach dem Willen des "Führers" sollte das Auto nicht mehr das Kennzeichen einer bestimmten Schicht, sondern Verkehrsmittel des Volkes sein. ${ }^{72}$ Hitler versprach, das Automobil, das bis dahin ein Luxusgefährt war, in ein „versöhnendes Werkzeug der Klassengegensätze“ zu verwandeln. ${ }^{73}$ Symbolisierte der Autobahnbau die geographische Einheit Deutschlands, so war das Volkswagen-Projekt der Versuch, die sozialen Konflikte zu befrieden, indem eine Überwindung der Klassenspaltung suggeriert wurde. Der in Aussicht gestellte Massenbesitz eines Fahrzeugs stellte außerdem ein Kompensationsangebot für unerfüllte demokratische Partizipationsrechte dar.

Mit seiner Ankündigung griff Hitler die bereits seit Ende der zwanziger Jahre diskutierte Idee eines für den Mittelstand erschwinglichen „Volksautos“ auf.74 Seit 1934 forderte er den "Reichsverband der Automobilindustrie“ in immer schärfer werdendem Ton auf, Pläne für einen Volkswagen auszuarbeiten..$^{75}$ Diese Art von Befehlsgebung im Stil staatlicher Reglementierung lehnte der Reichskanzler an anderer Stelle jedoch ab: Als Anfang 1934 der bevorstehende Zusammenbruch einer kleineren Firma in der Automobilindustrie angekündigt wurde, ließ Hitler mitteilen, er sei der Auffassung, dass der "technische Ausscheidungsprozess weitergehen muss, weil nur im freien Spiel der Kräfte die guten Fabrikate sich durchsetzen werden" ${ }^{76}$ In der Frage des Volkswagens wich Hitler von seinem Prinzip der marktwirtschaftlichen „Auslese“ ab. Marie Luise Recker betont

lers zur Aufkündigung des deutsch-polnischen Nichtangriffspaktes am 28.4. 1939, ebenda, S. 1161-1163.

71 Hitler auf der Internationalen Automobilausstellung 1934, zit. nach: Oppermann: Unter den Sturmstandern, S. 116. Der Volkswagen wurde in Zusammenhang mit der Autobahn gebracht. Er war wichtig, um die Nützlichkeit der wenig frequentierten Autobahn zu beweisen; vgl. Schulz: Verkehrswege, Verkehrsmittel und Vierjahresplan, S. 46.

72 Vgl. RDA (Hrsg.): „Das Kraftfahrzeug: Verkehrsmittel des ganzen Volkes“, S. 19.

73 Vgl. Motorwelt vom 17. 5. 1935: „Tagung der AIACR in Berlin“; RDA (Hrsg.): „Vollgas voraus!", S. 10.

74 Die Idee „Deutsches Volksauto“ entwickelten deutsche Ingenieure und Automobilindustrielle bereits Ende der zwanziger Jahre aus dem Bestreben heraus, den Absatzmarkt für Kraftfahrzeuge zu erweitern und potenzielle Käufer nicht an ausländische „Billig“-Anbieter wie Ford und Opel zu verlieren; vgl. Betz: Das Volksauto; Das Kraftfahrzeug in Wirtschaft und Heer, H. 12, 1929: „Wie soll der deutsche Volkswagen beschaffen sein?“

75 Die Entschlossenheit, mit der der Reichskanzler den Volkswagenbau vorantrieb, war den Industrievertretern bereits im Mai 1934 bewusst. In einer Besprechung des RDA wurde warnend bemerkt, dass die „einzelnen Firmen es gar nicht wagen dürften, dem Führer zu erklären, seine Volkswagen-Pläne seien derzeit undurchführbar [...]“; Aktennotiz über die Besprechung wegen des Volkswagens im RDA am 8. 5. 1934, StA Chemnitz, Auto Union AG 866. Auf der IAMA 1937 brach die Ungeduld aus Hitler heraus: „Entweder die sogenannte freie Wirtschaft ist fähig, diese Probleme zu lösen, oder sie ist nicht fähig, als freie Wirtschaft weiterzubestehen!“; RDA (Hrsg.): „Kraft des Motors, Kraft des Volkes“, S. 20.

76 Der Preußische Minister für Wirtschaft und Arbeit vom Januar 1934, Vermerk auf eine Anfrage in der Reichskanzlei nach Wünschen hinsichtlich der Reorganisation der Automobilindustrie, GStA PK, I. Ha Rep. 120, CVIII 1 Nr. 119, Bd. 5. 
die Ausnahmestellung des Volkswagenwerkes innerhalb des Sektors der Automobilindustrie:

„Es repräsentiert eine Variante von möglichen Beziehungen, nämlich eine von der politischen Spitze initiierte und durchgesetzte Unternehmensgründung, deren ursprüngliches Konzept, ein technisch modernes, preiswertes Familienauto in Massenfertigung zu produzieren, angesichts der Ausgangsbedingungen gegen jede ökonomische Vernunft war. ${ }^{477}$

Hitler setzte das Projekt gegen den Widerstand der Automobilindustrie durch. Die Deutsche Arbeitsfront (DAF) unter Führung von Robert Ley übernahm den Aufbau des Volkswagen-Werkes in Fallersleben, finanzierte es weitgehend aus eigenen Mitteln und propagierte den Volkswagen als „Kraft-durch-Freude-Wagen“. Ferdinand Porsche entwickelte den „KdF-Wagen“, der den „Volksgenossen“ ab 1938 im Rahmen von Sparverträgen angeboten wurde. Über 336000 Sparer folgten dem Slogan: „Fünf Mark die Woche mußt Du sparen, willst Du im eignen Wagen fahren." Nach vier Jahren und sieben Monaten sollte das Auto abgezahlt sein. Damit rückte die Regierung Hitler den Traum vom eigenen Auto in den unmittelbaren Erwartungshorizont der Bürger. Im Zustand großer Vorfreude prophezeite der Schriftsteller Werner Siebold: „In kurzer Zeit werden unzählige ,KdF'-Wagen von glücklichen Menschen des deutschen Volkes gesteuert werden, des Volkes, dessen Erfindungsgeist der Welt den Wagen ohne Pferd schenkte."78

Doch die für Aufrüstung verplanten Ressourcen und der Beginn des Krieges ließen den Traum vom eigenen Auto platzen. Das von der Deutschen Arbeitsfront aufgebaute Volkswagenwerk produzierte ab Dezember 1940 Kübelwagen für die Wehrmacht.

Das Motorrad blieb trotz aller Volkswagenpropaganda das motorisierte Fortbewegungsmittel des kleinen Mannes. Insbesondere Kleinkrafträder unter $250 \mathrm{ccm}$, die bis 1938 führerscheinfrei blieben und im Gegensatz zu mittleren und schweren Motorrädern in Anschaffung und Unterhalt auch für neue Käuferschichten erschwinglich waren. ${ }^{79}$

Die Haltung des Korpsführers des NSKK gegenüber dem Volkswagenprojekt war zwiespältig. Die hohe Zahl an Verkehrsunfällen rief seine Befürchtung hervor, Deutschland werde durch den Zuwachs an Kraftfahrzeugen in einem Verkehrschaos versinken. Er beteuerte: „Ich bin bestimmt ein fanatischer Mitkämpfer für den Volkswagen, aber zur Zeit fühle ich mich fast glücklich, diese Wagen nicht auch noch auf der Straße zu wissen." ${ }^{80}$ Hühnleins $Z$ weifel bezogen sich nicht nur auf verkehrssicherheitstechnische Bedenken. In einer nicht öffentlichen Stellungnahme gegenüber dem RDA kritisierte er, dass unter der Verbilligung die technische Qualitätsverbesserung der Autos leiden würde. Das probatere Mittel erschien Adolf Hühnlein, auf längere Sicht die Kaufkraft der Bevölkerung zu erhö-

77 Recker: Beweggründe und Zwangslagen des VW-Managements, S. 59.

78 Siebold: Wagen ohne Pferde, S. 331.

79 Vgl. Lützen: Radfahren, Motorsport, Autobesitz, S. 369. Das billigste Auto 1935 war der Opel P4, der ab Herbst 19361450 RM kostete. Er war von 1936 bis 1938 der meistgekaufte Pkw; vgl. Edelmann: Vom Luxusgut, S. 171.

80 Zit. nach: Oppermann: Unter des Sturmstandern, S. 139. 
hen. ${ }^{81}$ Das Argument der breiten Vermögensbildung teilte Hühnlein mit Volkswirtschaftlern, die als wichtigste Voraussetzung einer Massenmotorisierung die Erhöhung der individuellen Einkommensverhältnisse sahen. ${ }^{82}$

Der dritte Kritikpunkt, den Hühnlein in Bezug auf das Volkswagenprojekt erhob, war die geringe militärische Verwendungsfähigkeit der Fahrzeuge. Bereits im Mai 1934 brachten der NSKK-Korpsführer Hühnlein und Generaloberst von Blomberg gegenüber der Industrie zum Ausdruck, dass als Volkswagen nur ein „felddiensttauglich[es]" Fahrzeug von Interesse sein könnte. ${ }^{83}$ Damit gaben sie der Wehrpolitik Vorrang vor der Idee einer Mobilitätssteigerung der Bevölkerung.

Es wird deutlich, dass der Korpsführer des NSKK trotz anderslautender Beteuerungen nicht zu den „fanatischen Mitkämpfern“ des Volkswagens zu zählen war. Doch konnte dies nicht offen verlautbart werden. Es wäre nicht ohne politische Konsequenzen geblieben, wenn sich ausgerechnet das NSKK, der „Willensträger der Motorisierungsideen des Führers "84, in diesem entscheidenden Punkt gegen die Pläne Hitlers gestellt hätte. Das NSKK hatte nur wenige Berührungspunkte mit dem neu entstehenden Volkswagen. Dies wird auch daran deutlich, dass die Versuchsfahrten mit 30 Probewagen nicht vom NSKK, sondern von einem SS-Sturm unternommen wurden. ${ }^{85}$

Der alte und neue Gegensatz: Schiene - Straße

Eine bereits seit den zwanziger Jahren andauernde Debatte über die Frage, ob der Straße oder der Schiene der Vorzug gegeben werden solle und ob beide Verkehrsträger einer besonderen staatlichen Förderung bedürften, wurde auch im „Dritten Reich" weitergeführt. ${ }^{86}$ Das NS-Motorisierungsprogramm drängte den Eisenbahnverkehr in die Defensive. Im Verkehrsrat stellten die Anhänger der Motorisierung die Mehrheit. Der motorisierungsfreundliche Kurs schien den Konkurrenzkampf zwischen Schiene und Straße somit zugunsten der Straße entschieden zu haben. Hitler plädierte für den Aufbau einer differenzierten Infrastruktur: die Wirtschaft solle nicht mehr an die "Gegebenheiten des Massenverkehrs" gekoppelt sein, sondern der Verkehr müsse sich ,in Zukunft in zweckmäßigerer, individuellerer Form der Wirtschaft anpassen" .87

Die NS-Propaganda erklärte den „Krieg“ Straße gegen Schiene für beendet und ersetzte ihn durch den Formelkompromiss: Jeder Beförderungszweig übernimmt

81 Diese Überzeugung äußerte Hühnlein in einem Gespräch mit dem RDA am 12. 2. 1934; vgl. Edelmann: Vom Luxusgut, S. 179.

82 Weder kraftverkehrspolitische Maßnahmen noch die angestrebte Vollbeschäftigung seien geeignet, das „Auto ins Volk zu tragen“, so Hans Otto Wesemann: Die Verbreitungsaussichten des Automobils in Deutschland, S. 16-19.

83 Vgl. die Aktennotiz Carl Hahns von der Auto Union zur Besprechung im RDA betreffend den Volkswagen am 8. 5. 1934, StA Chemnitz, Auto Union AG 866.

${ }^{84}$ Aus einem Vortrag von Hühnlein, abgedruckt in: Der gewerbliche Kraftverkehr vom 7.6. 1937: „Das Nationalsozialistische Kraftfahrkorps im Dienste der Verkehrsgemeinschaft“.

85 Vgl. Edelmann: Vom Luxusgut, S. 207.

86 Vgl. Esch: Verkehrsmonopol oder freie Verkehrswirtschaft, S. $6 \mathrm{f}$.

87 Zit. nach Motorwelt vom 17. 5. 1935: „Tagung der AIACR in Berlin“. 
die Aufgabe, die er im Rahmen des Gesamtverkehrs am besten zu lösen vermag. 88 Dass eine „Versöhnung" von Straße und Schiene nicht zu einer Vereinheitlichung der Verkehrspolitik führte, ist daran ablesbar, dass das Unternehmen Reichsautobahnen unter Führung von Fritz Todt ein Tochterunternehmen der Reichsbahn war, das zu dieser in Konkurrenz trat. ${ }^{89}$ Todt hatte zur Durchsetzung seiner autobahnfreundlichen Politik 1935 den "Reichskraftwagen-Vetriebsverband" 90 initiiert, um direkten Einfluss auf den Güterverkehr mit Lkw nehmen zu können. Doch dem ab 1937 amtierenden Reichsverkehrsminister Julius Dorpmüller gelang es, den Verband mit seiner Tarifpolitik weiterhin an die Bahn zu binden. Reichsbahndefizite sollten unbedingt verhindert werden, weil sie den Haushalt erheblich belastet hätten. Die Reichsbahn behielt also de facto das Monopol im Güterfernverkehr. ${ }^{91} 1939$ wurden nur knapp 20 Millionen Tonnen mit Lastwagen befördert, das entsprach rund 3\% des Transportaufkommens von Bahn und Binnenschifffahrt. ${ }^{92}$ Damit lavierte die Verkehrspolitik zwischen 1933 und 1945 wie zuvor und auch danach zwischen den Interessen der Bahn und der Spediteure. ${ }^{93}$

\section{Metaphorik und Ideologie der Kraftfahrt im „Dritten Reich“}

\section{Motorisierung als Entwicklungsziel einer modernen Nation}

Das Auto entwickelte sich im 20. Jahrhundert zum Symbol für Geschwindigkeit, Individualität und Freiheit. Wie an Hitlers positiver Bewertung der individuellen Fortbewegung abzulesen ist, betrachtete auch der Nationalsozialismus das Automobil im Licht der Fortschrittssymbolik. Die Motorisierung wurde im „Dritten

88 In anderen Ländern gebe es aufgrund der Abwanderung des Güterverkehrs auf die Straße "Krieg“ zwischen der Straße und der Schiene. In Deutschland jedoch habe Hitler die Reichsbahn selbst für den Straßenverkehr interessiert; vgl. Schönleben: Die Straßen des Dritten Reiches, S. 81; Institut für Konjunkturforschung: Drei Jahre Motorisierung, S. 6.

89 Vgl. Kopper: Modernität oder Scheinmodernität?, S. 401.

90 Vgl. Der gewerbliche Kraftverkehr vom 21.12. 1936: „Aufbau und Entwicklung des Reichs-Kraftwagen-Betriebsverbandes“. Die Gründung des Verbandes unter Präsident Scholz ging auf das Gesetz über den Güterfernverkehr mit Kraftwagen vom 26. 7.1935 zurück. Der Verband regelte den gewerblichen Güterfernverkehr inklusive Konzessionen und Abrechnungsverfahren. Das Ziel bestand darin, für die Auslastung des vorhandenen Laderaums zu sorgen.

91 Um dem kraftfahrzeugfreundlichen Kurs zu entsprechen, legte auch die Reichsbahn ein Lkw-Beschaffungsprogramm auf. Die Reichsbahn war bestrebt, ihren Fahrzeugbestand auf die Gesamtzahl von 12000 Lkw zu steigern; vgl. Kopper: Modernität oder Scheinmodernität, S. 400; Aktenvermerk der Reichskanzlei vom November 1938, BArch R 43 II, 749a, Bl. 33.

92 Vgl. Schütz u. a.: Mythos RAB, S. 139.

93 Klaus Hildebrand weist auf die Eigenmacht des Konflikts hin, die sich der weltanschaulichen Überzeugung der NS-Machthaber entzogen habe; ders.: Die Deutsche Reichsbahn 1933-1945, S. 82. Vgl. zu dieser Frage auch die Untersuchung von Rohde: Transportmodernisierung contra Verkehrsbewirtschaftung, S. 304-308. 
Reich" als "lebendige Kraftäußerung einer modernen Nation" ${ }^{\text {} 94}$ präsentiert. Hitler sprach vom Auto als dem „wunderbaren Instrument modernster Verkehrs-

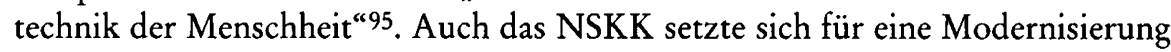
des Verkehrs ein. Als eine Art technisches Glaubensbekenntnis sind die Ausführungen in der Zeitung "Der NSKK-Mann“ vom 23. April 1938 zu lesen. Darin heißt es:

„Wir fürchten den Fortschritt nicht mehr, wir predigen ihn. Die großen Leistungen der Technik sind zu Grundbestandteilen der modernen Kultur geworden. [...] Kultur durch Technik, das ist das aufgeklärte Firmenschild des geläuterten Technizismus unseres Jahrhunderts. [...] Wir zählen die Überwindung der renitenten Fortschrittsfeindschaft zu den aktiven Erziehungsaufgaben des Korps. ${ }^{\text {"96 }}$

Die Fortschrittsbegeisterung war sowohl an der häufigen Verwendung des Attributs "modern" als auch an der Einschätzung der Entwicklungschancen moderner Technik abzulesen. Der NSDAP-Programmatiker Gottfried Feder sah zwar die Überproduktion und Arbeitslosigkeit in der Weltwirtschaftskrise als Anzeichen dafür, dass die industrielle Technikentwicklung ein prinzipielles Ende gefunden habe, Hitler schloss sich aber zu keiner Zeit dieser Endzeitstimmung an. Er glaubte vielmehr, der „Ersatz der menschlichen und animalischen Kraft durch den Motor" befände sich erst in seinem Anfangsstadium. ${ }^{97}$ Fortschrittshoffnungen im Sinne einer technischen Höherentwicklung legte auch NSKK-Korpsführer Hühnlein an den Tag, der im Motorsport Maßnahmen ablehnte, die der "Leistungsentfaltung von Mensch und Maschine" Fesseln auferlegten..$^{9}$ Auch die neue Reichsstraßenverkehrsordnung von 1934 wurde von den NS-Machthabern mit der Aussicht eingeführt, sie werde dem "technischen Fortschritt“ den Weg ebnen. ${ }^{99}$

Mochte sich die NS-Ideologie von moderner Kunst oder modernen Musikstilen distanzieren, in der Technik, insbesondere der Verkehrs- und der Wehrtechnik, definierte sie sich selbst als Teil der Moderne. Mehr noch - nach einer Beschreibung von Goebbels war die "NS-Revolution“ an die Spitze der technischen Entwicklungen getreten:

"Sie läuft heute nicht hinter der Entwicklung der Technik her, sie schreitet auch ihr wegweisend voran und zeigt ihr Richtung und Ziel. Denn der Nationalsozialismus ist die moderne politische Ausdrucksform des 20. Jahrhunderts. [...] Bei uns ist die Politik nicht Hemmschuh und Hindernis für die technische Entwicklung, sondern ihr kraftvollster und energischster Antrieb. Daher rührt die enge Verbundenheit des Nationalsozialismus mit allen Errungenschaften der modernen Technik." 100

\footnotetext{
94 Vgl. Hühnlein: Vortrag, gehalten am 16. 12. 1937, S. 2.

95 RDA (Hrsg.): „Wille wirkt Wunder“, S. 13.

96 Der NSKK-Mann vom 23. 4. 1938: „Fortschritt und Volksmoral“".

97 Weinberg (Hrsg.): Adolf Hitler. Reden, Schriften, Anordnungen, Bd. 2A, S. 84.

98 Mit diesem Argument lehnte Hühnlein technische Beschränkungen bei Rennwagen ab; Motorwelt vom 17. 5. 1935: „Die Tagung des AJACR in Berlin“.

99 Vgl. die Präambel der "Reichs-Straßenverkehrs-Ordnung“ vom 28. 5. 1934, RGBl. I 1934, Nr. 59.

100 RDA (Hrsg.): „Das Kraftfahrzeug: Verkehrsmittel des ganzen Volkes“, S. 7.
} 
Diese klare Positionierung war ein Schlag ins Gesicht der „Blut- und Boden-Fetischisten“, die von Bauerntum und vorindustriellen Zuständen träumten, und all jener, die Technik eher als Gefahr begriffen denn als Chance. Die nationalsozialistischen Machthaber sahen in der Motorisierung nicht nur einen Schlüssel zur Modernisierung des Landes, Motorisierung wurde überdies zu einem Identifikationsprojekt der politischen Bewegung, wie es der Slogan: „Kraft und Kraftfahrt - Zeichen des Dritten Reiches"101 sinnbildlich zum Ausdruck brachte. Der „Motor" war nach dem Willen der Motorisierungsförderer das Symbol für die Zukunftsfähigkeit, Entschlossenheit und Dynamik der neuen Regierung. „Der Partei fiel die Aufgabe zu, der gewaltige Motor im Innern Deutschlands zu sein, der Motor der seelischen Aufrichtung, der Motor der tätigen Hingabe, der Motor der steten Erweckung im Sinne des neu geschaffenen Reichs", schrieb Friedrich Stieve in seiner "Geschichte des deutschen Volkes".102

Die Verbundenheit der Nationalsozialisten mit der modernen Technik zeigte sich auch in der Übertragung technischer Fachausdrücke auf die politische Sprache des „Dritten Reiches“.103 Der zeitgenössische Beobachter Victor Klemperer registrierte eine Vielzahl mechanischer Begriffe, die vor allem von Goebbels in Bezug auf den Menschen und die Gesellschaft verwandt wurden. Zu den Begrifflichkeiten zählten „spuren“, etwas mit Bedeutung "aufladen“, Menschen die auf "Hochtouren laufenden Motoren" gleichen und das Wort "gleichschalten" - ein Schlüsselwort totalitärer Gesellschaftsgestaltung. ${ }^{104}$ Für eine bewusste Technisierung des Sprachgebrauchs spricht auch die Tatsache, dass im Gegensatz zu anderen Bereichen "Reinhaltungsmaßnahmen" zum Schutz der deutschen Sprache in der Technik nicht konsequent durchgeführt wurden. Eine bereits 1931 vom Deutschen Verband Technisch-Wissenschaftlicher Vereine angemahnte „Verdeutschung technischer Fremdwörter" hatte im „Dritten Reich“ nur wenig Aussicht auf Erfolg. „Verdichter“ an die Stelle des Kompressors zu setzen, „Richtmeister“ statt Monteur zu schreiben, "Tonfang" statt Mikrophon und "Zeitmaß" statt Tempo zu verwenden traf beim NSKK, das auf die Sprache der Motorisierung Einfluss nahm, auf Ablehnung. ${ }^{105}$ Auch wenn die NS-Sprache eine Vorliebe hegte für "Kraftbegriffe“, wie Kraftwagen und Kraftfahrzeug, wandte sich das NSKK doch gegen einen Übereifer bei der Verdeutschung von technischen Fremdwörtern und plädierte dafür, Begriffe wie Automobil, Differential, Zylinder und Tempo weiterhin zu benutzen. ${ }^{106}$ Die NS-Technikprotagonisten wollten sich im

101 Oppermann: Unter den Sturmstandern, S. 113.

102 Stieve: Geschichte des deutschen Volkes, S. 474.

103 Vereinzelt hatten bereits in den zwanziger Jahren technische Wörter Eingang in die Alltagssprache gefunden, wie z. B. „verankern“, „ankurbeln“, „Einstellung“; vgl. Klemperer: LTI, S. $162 \mathrm{ff}$.

104 Vgl. ebenda, S. 165. Klemperer kritisierte die Übertragung der Mechanik auf den Menschen, der dadurch zu einem technischen Apparat reduziert würde.

105 Vgl. Deutscher Verband Technisch-Wissenschaftlicher Vereine: Verdeutschung technischer Fremdwörter, Ausgaben von 1931, 1933 und 1934 (Typoskripte).

106 Vgl. Der NSKK-Mann vom 23. 7. 1938: „Zerknallgas-Treiblinge?“ Das NSKK verdeutsche alle technischen Fremdwörter soweit dies möglich sei, aber nicht um den Preis einer schlechten Verdeutschung. Dies teilte Kraus in seinem Schreiben der Reichsarbeitsge- 
Bereich der Motorisierung in keinem Fall dem Verdacht der Rückschrittlichkeit aussetzen.

Auch im Autodesign schwärmten die NS-Machthaber von der ,moderne[n] Linie". ${ }^{107}$ Modernität in der Formensprache verkörperte im 20. Jahrhundert die an die Aerodynamik angelehnte Stromlinienform. In Ansätzen wurde sie von den Automobilherstellern Opel, Volkswagen und Adler umgesetzt. England hingegen, so schrieb die deutsche Motorpresse, sei der „Feind der Stromlinie“, weil es sich dem „modernen" Wagenbau verschließe und Karosserien baue, die aristokratisch und teuer seien. ${ }^{108}$

Die Begeisterung für die Technik stand für den Nationalsozialismus nicht im Widerspruch zu einer Ablehnung der Moderne in anderen Gesellschafts- und Politikfeldern. Am deutlichsten ist der Unterschied zu anderen Bereichen an der Verwendung des Begriffs „Emanzipation“ abzulesen. Reichsverkehrsminister von Eltz-Rübenach prägte 1935 das Schlagwort von der „Emanzipation des Kraftwagens". ${ }^{109}$ Während die Emanzipation der Frau im nationalsozialistischen Empfinden als "unnatürlich" abgelehnt und die rechtliche Emanzipation der Juden im „Dritten Reich“ schrittweise rückgängig gemacht wurde, nahmen die nationalsozialistischen Politiker die Emanzipation des Autos freudig in ihren Zielkatalog auf.

An seine Grenzen stieß der technische Modernisierungswille dort, wo ausgewiesene Technokraten einen eigenen Herrschaftsanspruch erhoben. Die im Sommer 1933 gegründete Deutsche Technokratische Gesellschaft sprach sich für eine Führungsrolle des Technikers in der Gesellschaft aus. Die Nationalsozialisten teilten zwar den Widerstand der Planer, Techniker und Ingenieure gegen das Primat der kapitalistischen Gewinnmaximierung, doch waren auch sie nicht an einer $\mathrm{Au}$ tonomie der Technik interessiert, sondern erwarteten eine Unterordnung unter das Primat der Politik. ${ }^{110}$ Die Technokraten mussten sich der politischen Funktionalisierung der Technik durch die nationalsozialistischen Machthaber beugen. ${ }^{111}$ Das Machtmonopol und die politischen Bestrebungen der NS-Bewegung blieben mit den Zielen der Technokratiebewegung unvereinbar.

Eine weitere Grenze, an die eine positive Bewertung der modernen Technik stieß, war die Gleichsetzung mit dem Marktführer auf diesem Gebiet, den USA. Hitler bewunderte die Produktivität der amerikanischen Wirtschaft, den gesellschaftlichen Wohlstand und die Erfolgsgeschichte der amerikanischen Automo-

meinschaft der technisch-wissenschaftlichen Arbeit vom 9.6. 1936 mit, betr. Verdeutschungsliste, BArch NS 24/114.

107 Hühnlein: Vortrag, gehalten am 16. 12. 1937, S. 2.

108 Vgl. Motor, H. 1, 1939: „Aristokratie und Stromlinie!““ Die Stromlinienform z. B. beim Opel Olympia von 1935 stand für Modernität; vgl. Fack: Automobil, Verkehr und Erziehung, S. $305 \mathrm{f}$.

$109 \mathrm{Vgl}$. Brandenburg: Wandlungen im Kraftverkehr, S. 14.

110 Vgl. Sieferle: Die Konservative Revolution, S. 209.

111 Die Mitglieder der Deutschen Technokratischen Gesellschaft hatten zahlreiche Differenzen mit den Nationalsozialisten; vgl. Hortleder: Das Gesellschaftsbild des Ingenieurs, S. $220 \mathrm{ff} ., 263$. 
bilproduzenten. ${ }^{112}$ Doch das Bild von den Vereinigten Staaten trug auch ausgeprägte Negativzüge. Amerika war Sinnbild für Vermassung, Plutokratie, Feminismus, jüdisches Kapital, Demokratie und „Rassenvermischung“ - nach nationalsozialistischem Dafürhalten verabscheuungswürdige Entgleisungen westlicher Zivilisation. ${ }^{113}$ Der amerikanische Weg in die technische Moderne war nicht zu trennen von der Entwicklung von Demokratie und Liberalismus und der Idee bürgerlicher Freiheiten. Amerikanische Technik war per definitionem republikanische Technik. ${ }^{114}$ Hitler lehnte das amerikanische Modell in Bezug auf die „materialistisch-kulturlose" Lebensform und den ausbeuterischen Kapitalismus ab. Die Nationalsozialisten wollten Deutschland ähnlich erfolgreich in die technische Moderne führen wie die USA dies vorgemacht hatte, jedoch mit dem entscheidenden Unterschied, dass die Technik nicht republikanische, sondern deutsch-völkische Prägungen besitzen sollte.

\section{Motorisierung und Technik als deutsche Kulturgüter}

Unter den Intellektuellen der Weimarer Republik herrschte die weit verbreitete Ansicht, das technische Zeitalter sei an seine Grenzen gestoßen. Diese Meinung vertrat der Geschichtsphilosoph Oswald Spengler, der Anfang der dreißiger Jahre das Unbehagen der Gesellschaft an der Technik so beschrieb:

„Man wendet sich zu einfacheren, naturnäheren Lebensformen, man treibt Sport statt technischer Versuche, man haßt die großen Städte, man möchte aus dem Z wang seelenloser Tätigkeiten, aus der Sklaverei der Maschine, aus der klaren und kalten Atmosphäre technischer Organisation heraus. " 115

In der Technikdiskussion der Weimarer Republik ${ }^{116}$ wurde zumeist die falsche Anwendung der Technik kritisiert, weniger die Technik an sich verworfen. Technikskeptiker, die die Naturzerstörung anprangerten, kamen in den zwanziger Jahren aus der Lebensreform- und Heimatschutzbewegung sowie aus der bürgerlichen Jugendbewegung. Ein wichtiger Vertreter einer lebensphilosophisch inspi-

$112 \mathrm{Vgl}$. auch Hachtmann: „Die Begründer der amerikanischen Technik sind fast lauter schwäbisch-alemannische Menschen“, S. $37 \mathrm{f}$.

$113 \mathrm{Vgl}$. zum Amerika-Bild der Nationalsozialisten das Einleitungskapitel von Lüdtke u.a. in dem Buch: Amerikanisierung, S. 7-33; Schäfer: Amerikanismus im Dritten Reich; Trommler: Amerikas Rolle im Technikverständnis der Diktaturen; Gassert: Amerika im Dritten Reich. Ähnlich ambivalent wie die Haltung der Nationalsozialisten zu den USA war auch ihre Einstellung zur Großstadt: Einerseits angefeindet als kosmopolitischer Schmelztiegel und Ort „seelischer Entwurzelung“, war sie doch andererseits unverzichtbar als Ansiedlungspunkt moderner Industrie und innovativer Technik; vgl. dazu: Marchand: Nationalsozialismus und Großstadtfeindschaft; Fack: Automobil, Verkehr und Erziehung, S. $327 \mathrm{f}$.

114 Vgl. Schlüter: Erfindergeist und Technikkritik, S. 20.

115 Spengler: Der Mensch und die Technik, S. 81.

116 Pro und contra Technik erschien mannigfaltige Literatur. Vgl. dazu Jebens: Das Testament der Technik; Schumacher: Der „Fluch“ der Technik; Krannhals: Der Weltsinn der Technik. Die Erkenntnis, dass Technik nicht glücklich macht, vertrat Böttcher: Das Scheinglück der Technik. Die persönliche Verantwortung des Menschen bei der Technikanwendung betonte Hartmann: Technik und Staat. 
rierten Zivilisationskritik war Ludwig Klages. Seine Kritik wandte sich gegen die zunehmende Monotonie der Arbeitsvorgänge in der Fabrik und gegen eine zunehmende Mechanisierung aller Lebensbereiche. ${ }^{117}$ Klages bezeichnete Industrie und Technik als tote Materie mit lebensvernichtenden Folgen für Natur, Kultur und Volkstum. ${ }^{118}$

Im Unterschied zu kulturpessimistischen Strömungen, die eine rückwärts gerichtete Fluchtbewegung à la Wandervogel einschlugen, erkannten wichtige Vertreter der so genannten „Konservativen Revolution“ “119, allen voran Ernst Jünger, in der Technik Leistungskraft, Machtmittel und Lebensinstinkt. ${ }^{120}$ Mit deutlich apokalyptischem Unterton favorisierten sie in ihren technikphilosophischen Schriften eine Haltung der aktiven Bejahung - mindestens aber des tapferen Ertragens der Technik. ${ }^{121}$

Der Kapitalismuskritiker Werner Sombart hingegen äußerte Vorbehalte gegen eine weitere Ausbreitung der Technik, die er auch in der NS-Zeit erhob. Er sprach sich in seinem Buch „Die Zähmung der Technik“, das 1935 erschien, unter anderem gegen eine ungehemmte Motorisierung aus. ${ }^{122}$ Sombart beklagte die Verherrlichung der Technik durch Rassentheoretiker des „Völkischen Beobachters“ und plädierte, wie bereits der Titel des Buches aussagt, für eine Eindämmung der Technik durch eine stärkere Reglementierung des Staates. ${ }^{123}$

117 Rohkrämer: Eine andere Moderne?, S. 168 ff.; Sieferle: Fortschrittsfeinde?, S. 210.

118 Vgl. zu Klages und seinem Werk „Der Geist als Widersacher der Seele“ (1929-1933) Sieferle: Die Konservative Revolution, S. $214 \mathrm{f}$.

119 Als „Konservative Revolution“ wird eine geistig-politische Bewegung der Weimarer Republik bezeichnet, zu der antiparlamentarische, antidemokratische, völkisch-konservative und nationalrevolutionäre Gegner der Republik zählten. Die bekanntesten Protagonisten waren Ernst Jünger, Oswald Spengler, Carl Schmitt, Hans Freyer und Werner Sombart. Kennzeichen dieser Geistesströmung sei der Versuch gewesen, so Jeffrey Herf in seinem Buch „Reactionary Modernism“, die technischen Errungenschaften der Moderne zu preisen und die politischen zu verwerfen. Dass es jedoch unter den genannten Vertretern höchst unterschiedliche Haltungen bezüglich der technischen Moderne gegeben hat, zeigt Sieferle: Die Konservative Revolution.

120 Dupeux: ,Kulturpessimismus', S. $292 \mathrm{f}$.

121 Im Unterschied zu Jüngers aktiver Bejahung der Möglichkeiten der Technik steht bei Spengler die passive und pessimistische Haltung im Mittelpunkt; vgl. Spengler: Der Mensch und die Technik.

$122 \mathrm{Vgl}$. Sombart: Die Zähmung der Technik, S. 29. Sombart ging davon aus, dass die Technikentwicklung an ihr Ende gelangt sei und nunmehr negative Folgen hervorbringen würde. Aus diesem Grund sprach er sich für eine Dezentralisierung und „Re-Agrarisierung der Wirtschaft“ aus; vgl. auch Sieferle: Die Konservative Revolution, S. 212.

123 Sombart definierte „Zähmung der Technik“ als „eine Technopolitik, die an die Stelle des Laissez-faire- und Laissez-aller-Prinzips, das heute noch - und nur noch - in dem Bereich der Technik gilt, eine bewußte Einflußnahme des Staates auf die Technik setzt und die bemüht ist, auch und gerade die Technik in den Dienst des Gemeinwohls zu stellen, d.h. also auch und gerade der Technik gegenüber den obersten Grundsatz des Nationalsozialismus ,Gemeinnutz geht vor Eigennutz` zur Geltung zu bringen“; Sombart: Die Zähmung der Technik, S. 35. Im Gegenzug kritisierte Fritz Nonnenbruch im Völkischen Beobachter Sombart für seine Forderung, geschützte Landschaften für Automobile und Motorräder zu sperren, vgl. die Rezension von Nonnenbruch im Völkischen Beobachter vom 5. 10. 1934 über das Buch „Deutscher Sozialismus“ von Werner Sombart. 
Goebbels wies die bürgerliche Skepsis und Ängstlichkeit gegenüber der Technik in einer Grundsatzrede auf der Internationalen Automobil- und Motorradausstellung 1939 zurück und beschwor eine Symbiose von Technik und Nationalsozialismus:

„Wir leben in einem Zeitalter, das zugleich romantisch und stählern ist, das seine Gemütstiefe nicht verloren, andererseits aber auch in den Ergebnissen der modernen Erfindung und Technik eine neue Romantik entdeckt hat. Während die bürgerliche Reaktion der Technik fremd und verständnislos, wenn nicht ablehnend, gegenüberstand, während moderne Skeptiker in ihr überhaupt die tiefste Ursache des Verfalls unserer europäischen Kultur erblicken zu müssen glauben, hat der Nationalsozialismus es verstanden, der Technik ihr seelenloses Gepräge zu nehmen und sie mit dem Rhythmus und mit dem heißen Impuls unserer Zeit zu erfüllen." 124

Ein wichtiges Ziel der nationalsozialistischen Technikphilosophie bestand darin, Kritiker mit der als kalt und seelenlos angefeindeten Technik zu "versöhnen“. Goebbels beschwor eine Synthese aus Stählernheit und neuer Romantik. Das NSKK-Presseorgan „Der NSKK-Mann“ brachte die NS-Motorisierungsideologie auf die griffige Formel: „Volk, Blut und Rasse vertragen sich wohl mit Autorennen, Volkswagen, Benzin und Flugrekorden." 125

Der völkischen Sehnsucht nach einer "gesunden“ Beziehung zwischen Natur, Kultur und Technik kam man entgegen, indem man Straßen „organisch“ in die Landschaft einfügte und mit einem Begriff wie "Autowandern" an die Traditionen der Natur- und Lebensreformbewegung anknüpfte. ${ }^{126}$ Die Propaganda bezeichnete die NS-Technik als „schöpferische Arbeit an der Natur im Dienste der Kultur" 127 und versuchte die Elemente Natur, Kultur und Technik in einen harmonischen Dreiklang zu bringen. Mit diesem Versöhnungsvokabular versprach der Nationalsozialismus die Rücknahme der psychischen und kulturellen Zumutungen der modernen Industriegesellschaft. Doch konnten die Härten der Technik und des sozialen Wandels auf diese Weise nicht gemildert, sondern nur kulturell überdeckt werden.

Die Integration der Technik in das nationalsozialistische Gesellschaftsideal wurde durch die Einbettung der Motorisierung in das deutsche Kulturerbe erleichtert. Reichsverkehrsminister Freiherr von Eltz-Rübenach wandte sich speziell an Motorisierungskritiker mit völkischem Hintergrund:

124 Zit. nach Deutsche Kraftfahrt vom März 1939: „Die größte Autoschau der Welt“. Ähnlich formulierte von Eltz-Rübenach 1934: „Das ist die Aufgabe unserer Tage: das mechanische Zeitalter zu beseelen mit dem Geiste eines nationalen Sozialismus und dadurch der neuen Zeit ihren inneren Gehalt und ihren Wert zu geben“; HStA Stuttgart, E 130b, Bü 3120 a.

125 Der NSKK-Mann vom 23. 4. 1938: „Fortschritt und Volksmoral“.

126 Schütz bezeichnete „Autowandern“" treffend als "motorisierte Fortsetzung des, Wandervogels“"; Schütz u. a.: Mythos RAB, S. 124. Ausschlaggebend für die organische Streckenführung der RAB und die Einrichtung von Landschaftsanwälten waren die genannten Versöhnungsziele und der Wunsch nach Ästhetisierung. Ob man dies als Ausdruck modernen ökologischen Problembewusstseins werten kann, wie Michael Prinz dies tut, ist fraglich; vgl. ders.: Die soziale Funktion moderner Elemente, S. 315.

127 Gungler: Technik und Politik im neuen Staat, S. 14. 
„Es gibt Menschen, welche in einer Steigerung der Technisierung, der Motorisierung des Verkehrs eine Gefahr sehen für die Erhaltung seelenhafter Verbundenheit von Blut und Boden, eine Einbuße an jenen besten Volkseigenschaften, die sich in einem industrielosen, freien, lustigen Bauernstaat in vollendeter Reinheit zeigen. Ich muß solchen Gedanken nicht nur als Ingenieur, sondern als deutscher Reichsminister nachdrücklich widersprechen. Die Technik und mit ihr die Motorisierung sind Errungenschaften der Kultur.“128

Die Verlautbarungen, die sich seit der Machtübernahme der Nationalsozialisten mit dem Themenbereich Motorisierung befassten, ließen kaum eine Gelegenheit aus, Autos als deutsche Kulturgüter und Autobahnen als „Willensausdruck unseres maschinentechnischen Kulturschaffens" 129 zu preisen. Die Motorisierung wurde von Hitler zu einem Gradmesser für die Kulturstufe eines Volkes erklärt: „Wenn man früher die Lebenshöhe eines Volkes oft nach der Kilometerzahl der Eisenbahnen zu messen suchte, wird man in der Zukunft die Kilometerzahl der für den Kraftverkehr geeigneten Straßen anzulegen haben."130

Die NS-Propaganda huldigte dem Kraftwagen nicht nur als genialem Produkt deutscher Arbeit, sondern betonte auch dessen deutsche Ursprünge. Dabei stand die Pionierleistung der deutschen Erfinder Gottlieb Daimler und Carl Benz im Zentrum der Würdigung. ${ }^{131}$ Daimler wurde anlässlich seines 100 . Geburtstages als Begründer der „deutschen Kraftfahrt“ posthum geehrt. In seiner Geburtsstadt Schorndorf fanden im April 1934 Feierlichkeiten statt, zu der die politische Prominenz, namentlich der Reichsverkehrsminister, Korpsführer Hühnlein, Reichsstatthalter Murr und Ministerpräsident Mergenthaler anreisten. ${ }^{132} \mathrm{Im}$ Gedenken an Daimler erschienen zahlreiche, zum Teil antisemitisch gefärbte Festschriften und Biografien, die Daimler als Kronzeugen für die nationalsozialistische Wirtschaftsauffassung im Kampf gegen den Kapitalismus und das Judentum instrumentalisierten. ${ }^{133}$

Die NS-Propaganda stellte auch bald nach der Machtergreifung eine Verbindung zwischen der Förderung der Motorisierung durch die Nationalsozialisten und dem Auto-Pionier Carl Benz her. Im April 1933 wurde in Mannheim das Benz-Denkmal errichtet. Zur Enthüllung rollten die Kraftfahrer der Motor-SA auf Motorrädern in Dreierreihen in die Stadt, gefolgt von einem Korso historischer Wagen, die von Industriellen und „Herrenfahrern“ gelenkt wurden. ${ }^{134}$ An

128 Reichsverkehrsminister von Eltz-Rübenach auf dem Begrüßungsabend der Automobilindustrie am 10. März 1934; RDA (Hrsg.): „Vollgas voraus!“, S. 15.

129 Krüger: Die Straßen der Welt, S. 60.

130 RDA (Hrsg.): „Kraftfahrt tut not!“, S. $10 \mathrm{f}$.

131 Ebenda, S. 8.

132 Vgl. die Pressesammlung zu den Gottlieb-Daimler-Feierlichkeiten, HStA Stuttgart, E 130 b, Bü 3120 a.

133 In einem Schreiben des Völkischen Beobachters vom 20.3. 1934 an den Ministerpräsidenten Mergenthaler betreffend einer von Willi Ehmer verfassten Festschrift wird aus den Tagebüchern Daimlers von 1891-95 wie folgt zitiert: „Ihr Ingenieure laßt euch nicht durch die Juden und Kapitalisten unterdrücken, wie man es bei mir versucht hat in unerhört frecher Weise [...]“; HStA Stuttgart E 130b, Bü 3120 a. Paul Siebertz verfasste eine Biografie mit starken antisemitischen Nebentönen; ders.: Gottlieb Daimler. Angriffsziel war der „böse“ Jude Kilian Steiner, der 1863 die Deutsche Partei in Württemberg gegründet und für das Berliner Bankhaus Delbrück, Leo \& Co gearbeitet hatte; ebenda, S. $195 \mathrm{ff}$.

134 Horch: Ich baute Autos, S. 310 f. 
der Aufstellung des Festzugs und der Veranstaltungsregie wird deutlich, dass die Motor-SA und das NSKK sich die erste Stelle in der Erbfolge der deutschen AutoPioniere sichern wollten. Das Institut für Konjunkturforschung erkannte in den Förderungsmaßnahmen der Nationalsozialisten die Erfüllung des Aufbauwerkes von Daimler und Benz: „Das aber ist der Sinn all dessen, was in den letzten drei Jahren in Deutschland geschah, und so wurde dem deutschen Volk ein halbes Jahrhundert nach Daimler und Benz das Kraftfahrzeug zum zweiten Mal geschenkt." 135

Eine als "deutsch" definierte Technik zeichnete sich erstens durch ihre deutschen Ursprünge aus und zweitens durch ihren völkischen Gehalt. Der „Rassegedanke" war für den Nationalsozialismus nicht nur Schlüssel zum Verständnis der Weltgeschichte, sondern auch zur Interpretation der Technikgeschichte. Der Wirtschaftspublizist Fritz Nonnenbruch behauptete, dass sich in der Technik die "Rasse“ als besonders initiativ erwiesen habe. ${ }^{136}$ Der NS-Technikpropagandist Karl Arnhold verbreitete die gleiche Meinung: „Schöpferische Technik betreibt nur, wem sie im Blute liegt." ${ }^{137}$ Die technischen Erfindungen, so Arnold weiter, seien ein Verdienst der „nordischen Rasse“. Auch Fritz Todt pries in seinem Vortrag auf der 4. Reichstagung der Nordischen Gesellschaft am 21. Juni 1937 den nordischen Menschen als Erfinder und Entdecker. Nicht ein wirkliches, materielles Verkehrsbedürfnis treibe den Menschen zum Kraftwagen, sondern „der letzte Schuß alten Wikingerblutes“. ${ }^{138}$ Adolf Hitler sah die technischen Errungenschaften als Ausdruck "arisch-germanischer" Überlegenheit an. Dazu führte er in "Mein Kampf“" aus: "Was wir heute an menschlicher Kultur, an Ergebnissen von Kunst, Wissenschaft und Technik vor uns sehen, ist nahezu ausschließlich schöpferisches Produkt des Ariers. "139 Diese Überzeugung war ein wichtiger Bestandteil seines "Herrenmenschendenkens" und harmonierte mit seiner Verehrung für den Autobauer Henry Ford, der bereits Anfang der zwanziger Jahre seine antisemitische Haltung offen propagiert hatte. ${ }^{140}$

Es ging nicht nur darum, die Motorisierung in ein deutsch-völkisches Kulturerbe einzubetten, sondern auch, dieses Kulturerbe "rasserein“ zu halten. Innerhalb einer als "deutsch" titulierten Technik, die sich an „Rasseprinzipien“ orientierte, war kein Platz für Techniker jüdischer Herkunft. Bereits vor der NSMachtübernahme hatte der NS-Technikdiskurs deutliche antisemitische Züge. Peter Schwerber sprach sich in seinem 1930 veröffentlichten Buch „Nationalsozialismus und Technik“ gegen eine "jüdisch-materialistische Umklammerung“ der Technik aus. ${ }^{141}$ Anknüpfend an diesen Gedankengang stellte Ministerialrat

135 Institut für Konjunkturforschung: Drei Jahre Motorisierung, S. 16.

136 Vortrag von Fritz Nonnenbruch, abgedruckt in: Vorträge beim 3. Gautag der Technik in Stuttgart 1937, S. 10.

137 Arnhold: Die Technik ruft, S. 11.

138 Todt: Der nordische Mensch und der Verkehr, S. 398.

139 Hitler: Mein Kampf, Bd. 1, S. 317.

140 Vgl. Ford: Der internationale Jude. Mehr zur nationalsozialistischen Einschätzung Henry Fords bei Hachtmann: „Die Begründer der amerikanischen Technik sind fast lauter schwäbisch-alemannische Menschen“, S. 41-44.

141 Schwerber: Nationalsozialismus und Technik, S. 38. 
Konrad Nonn 1935 die Behauptung auf, die Technik habe den Juden nach dem Handel eine neue Form der Bereicherung geboten. Dies habe den Staat und die Arbeiter in eine abhängige Position gegenüber dem ,jüdisch-internationalen Kapitalismus" gebracht. Im Gegensatz zu den "Zersetzungsoperationen“ des Judentums nutze das „Dritte Reich“ die Technik nun für das Wohl des Gesamtvolkes. Der Centralverein deutscher Staatsbürger jüdischen Glaubens wehrte sich 1935 gegen derlei Anschuldigungen. Er verwies darauf, dass deutsche Juden wie Heinrich Hertz, der 1886 die elektrischen Wellen entdeckte, Emil Berliner, der 1889 das Mikrofon erfand, und Siegfried Marcus, der 1875 den ersten Benzinmotor baute, einen großen Anteil an der Entwicklung einer gemeinnützigen Technik gehabt haben. ${ }^{142}$ Doch die in den jüdischen Presseorganen verbreiteten Gegendarstellungen verpufften angesichts der massiven antisemitischen Propaganda. Aufgrund der immer schwieriger werdenden Arbeits- und Lebensbedingungen verließen rund 3000 jüdische Ingenieure ihre Heimat Deutschland. ${ }^{143}$

Um das nationalsozialistische Technikverständnis noch präziser konturieren und in den zeitgenössischen Technikdiskurs einordnen zu können, ist es hilfreich, auf den Schriftsteller und Technikbefürworter Ernst Jünger zurückzukommen. 1932 erschien sein Großessay „Der Arbeiter. Herrschaft und Gestalt“. Liest man den „Arbeiter" als „Entwurf eines ästhetisch-faschistischen Modernitätskonzepts "144, wie es der Literaturwissenschaftler Uwe-K. Ketelsen vorschlägt, bietet sich ein Vergleich mit dem Nationalsozialismus an. Ernst Jünger antwortete auf eine sich immer stärker technisierende Welt nicht mit romantischem Protest, sondern plädierte dafür, dass der Mensch sich den Risiken und den Möglichkeiten der Technik in einer Haltung des "heroischen Realismus" 145 stellen sollte. Um diese Herausforderung zu bewältigen, bedürfe es, so Jünger, eines neuen menschlichen Typus - des "Arbeiters" - der nach der Zerstörung der bürgerlichen Welt an die Stelle des „Bourgeois“ tritt. ${ }^{146}$

Auch die nationalsozialistische Ideologie schrieb den Ingenieuren, Technikern und Industriearbeitern eine neue, bedeutendere Rolle in der Arbeitswelt des „Dritten Reiches“ zu. Gemeinsam war dem „Arbeiter" und der NS-Technikideo-

142 Vgl. die Reaktion auf Nonns Anschuldigungen in der Central-Vereins-Zeitung. Blätter für Deutschtum und Judentum, Ausgabe A vom 28. 2. 1935: „Schöpferische Technik“. Neben Emil Berliner (1852-1929) und Siegfried Marcus (1831-1893) könnte man noch David Schwarz (1845-1897) nennen, der 1897 das erste lenkbare Luftschiff baute, Rudolf Goldschmidt, der als erster vor dem Ersten Weltkrieg drahtlos von Europa nach Amerika telegrafierte oder Hermann Aron (1845-1913), der den Drehstromzähler erfand und die Grundlagen für das Differenzialgetriebe - einen wesentlichen Bestandteil des Kraftwagens - legte; vgl. Karpe: Technik, S. 710-719.

143 Vgl. Ludwig: Politische Lösungen für technische Innovationen 1933-1945, S. 340. Der Zeitpunkt der Entlassung war vom Einfluss nationalsozialistischer Vertrauensleute in der Firma, vom Bekanntheitsgrad des jüdischen Ingenieurs und seiner Position abhängig; vgl. Mock: Technische Intelligenz im Exil 1933-1945, S. 64. Siehe auch die Studie von Erik Eckermann über Nathan Stern, den Technischen Direktor der Teves GmbH Frankfurt, die Autoteile herstellte. Stern floh 1937 nach England; vgl. Eckermann: Nathan S. Stern.

144 Ketelsen: Literatur und Drittes Reich, S. 259.

145 Jünger: Der Arbeiter, S. 41.

146 Sieferle: Die Konservative Revolution, S. 155. 
logie die Bewunderung für die Errungenschaften der Technik und die Wertschätzung der Technik als kulturelle Leistung. ${ }^{147}$

Auch wenn die Technikbejahung und die Charakterisierung der Arbeit als „technische Machtproduktion“148, wie sie Ernst Jünger vornahm, mit dem nationalsozialistischen Technikverständnis korrelierten, kann im Nationalsozialismus dennoch nicht die Verwirklichung der Jüngerschen Prophetie gesehen werden.

Die Unterschiede sind evident und lassen die Spezifik der NS-Technikideologie klar hervortreten. Nach Erscheinen des Buches kritisierten nationalsozialistische Rezensenten die kühle Beschreibung der Technik und die in aller Monstrosität in Aussicht gestellten "technischen Landschaften“, die eine "Versöhnung" von Technik und Natur unmöglich erscheinen ließen. Ein wesentlicher Unterschied zum Nationalsozialismus bestand überdies darin, dass Jünger für die Technik eine "planetarische“ Gültigkeit beanspruchte, 149 die nach seiner Überzeugung eine Überwindung jeglicher Nationalismen zur Folge haben musste. Dies deckte sich nicht mit dem übersteigerten Nationalismus in der NS-Ideologie. Eine weitere entscheidende Differenz lag in den unterschiedlichen Wegen, die zu einer technisierten Gesellschaft führen sollten. Der Aufstieg eines technophilen, neuartigen Menschengeschlechts war im Denken Jüngers abhängig von der Einstellung des Arbeiters zur Technik und nicht von Rassentheorien, die für die NS-Führung, wie gezeigt, auch im Bereich der Technik elementarer Bestandteil und Antrieb waren..$^{150}$

Die Nationalsozialisten verwandelten das technische Schlagwort „Motorisierung " in eine politisch-kulturelle Weltanschauung. Die Einstellung zur Motorisierung erhielt eine politische Dimension. In der motorisierungsfreundlichen Sprache sind zahlreiche Ideologeme enthalten, die es rechtfertigen, von einer „NS-Motorisierungsideologie" zu sprechen. Dies meint nicht nur eine Ideologisierung der Technik im Sinne einer deutsch-völkischen Technikbegründung und „Arisierung“ der Technik, sondern auch eine Technisierung der Ideologie in Form einer Technisierung der politischen Sprache und Identifikation mit dem Motor als Herrschaftssymbol des Nationalsozialismus.

147 „In diesem Sinne läßt sich allerdings der Ausspruch wagen, daß bereits heute inmitten der Zuschauerringe eines Lichtspieles oder eines Motorrennens eine tiefere Frömmigkeit zu beobachten ist, als man sie unter den Kanzeln und vor den Altären noch wahrzunehmen vermag“; Jünger: Der Arbeiter, S. 166.

148 Merlio: Der sogenannte ,heroische Realismus' als Grundhaltung des Weimarer Neokonservatismus, S. 277.

149 Vgl. Jünger: Der Arbeiter, S. 205. Die Technik, so Jünger, greife traditionelle Bindungen wie das Bürgertum, das Christentum und den Nationalismus an; ebenda, S. 161.

150 Vgl. Sieferle: Die Konservative Revolution, S. 159-161. 


\section{Das NSKK - Der „Banner- und Willensträger der Motorisierung“}

\section{Der Beitrag des NSKK zur Motorisierungsideologie}

Aufgrund der Konzentration auf praktische Aufgaben vor 1933 und dem untergeordneten Status innerhalb der SA entfaltete das NSKK keinen Einfluss auf das Motorisierungsprogramm, das Hitler bei seiner Eröffnungsrede 1933 verkündet hatte. Obgleich einige Redner auf den alljährlichen Automobilausstellungen die Arbeit des NSKK lobten und Korpsführer Hühnlein selbst im Rahmen der IAMA Vorträge hielt, erwähnte Hitler selbst das NS-Kraftfahrkorps in seinen Eröffnungsreden zwischen 1933 und 1939 mit keinem Wort. Das NSKK zählte nicht zu den originären Ideologieproduzenten im „Dritten Reich“. Vielmehr übernahm es den vorgegebenen Kurs der Reichsführung und wiederholte die von Hitler und Goebbels vorgetragene Technikideologie. Die Bedeutung des NSKK bestand, technikideologisch gesehen, vorwiegend in einer Multiplikatorenfunktion.

Die Begriffe „Motorisierung“ und „Technik“ erscheinen in den Publikationen und Reden von NSKK-Funktionären der Vorgabe entsprechend in erster Linie als kulturelle, nicht als technische Begriffe. Deutschland sollte nach Überzeugung des Korpsführers ein Motorisierungsniveau erreichen, das der , hohen Kultur und $\mathrm{Zi}$ vilisation unseres Volkes" gerecht werde. 151 Ähnlich dem Goebbelschen Gedankengang von der stählernen Romantik im „Dritten Reich“ wies der Technikbeauftragte des NSKK Erwin Kraus diejenigen in die Schranken, die behaupteten, der modernen Zeit sei die Poesie und Romantik verloren gegangen. Zur Widerlegung deutete er auf den „lebendigen Pulsschlag“ der Zeit, deren Poesie die Technik sei. ${ }^{152}$ Diese Poesie, die das Verhältnis von Natur und Technik ästhetisierte, nahm mitunter kitschige Züge an, wie die Beschreibung einer Geländefahrt zeigt:

„Der harte, starke und für uns so berauschend schöne Klang des Sportmotors hallte wider von den fliegenden Grünmassen der Baumkronen [...]. In den Kurven, wenn die Baumreihen herumschwangen wie die Speichen eines großen Rades, sangen die Reifen ihr erregend vibrierendes Lied, dem singenden Flügelschlag großer Vögel vergleichbar [...]."153

Trotz Technikbewunderung war es dem NSKK wichtig, eine Grenze zwischen gesunder Technikbegeisterung und ungesunder Technikhörigkeit zu ziehen. Ein Kommentar in der Zeitung „Der NSKK-Mann“ forderte:

„Wir sträuben uns bewußt dagegen, daß einmal die Technik unser Dasein beherrschen könnte. Denn wir wollen keine technische Zivilisation, wie wir sie schaudernd drüben im Land der unbegrenzten Möglichkeiten sehen, sondern eine Kultur, die aus dem Herzen kommt. In gleicher Weise kämpfen wir dagegen an, daß unsere Sprache aus nüchterner Zweckmäßigkeit heraus „technisiert" wird. Wir sind keine Roboter und Maschinenmenschen." 154

151 Vgl. Hühnlein: Die vor- und nachmilitärische Wehrertüchtigung des NSKK, S. 79.

152 Vgl. Völkischer Beobachter vom 5. 3. 1936: „Die Technik ist die Poesie unserer Zeit“.

153 Deutsche Kraftfahrt vom Juli 1938: „Motorsportwoche!“

154 Der NSKK-Mann vom 7.6. 1941: „Sprache und Kultur“. 
Amerikanische Zivilisation wird hier als Synonym für kühle Rationalität, Kontrollverlust und Entfremdung angesehen. Deutsche Kultur, die „Kultur, die aus dem Herzen kommt“, erscheint als „Kuschelfaktor“", der der kalten Technik und der instrumentellen Rationalität ihren Schrecken nimmt. Der Korpsführer Adolf Hühnlein betonte die lebendige Beziehung zwischen dem „Motormann“ und seinem Kraftfahrzeug: „Er [der NSKK-Mann] sieht in ihm kein totes Wesen, sondern lebendige Kraft und den treuen Gefährten. " ${ }^{155}$ Die lebendige Kraft des Motors hatte auch erzieherische Funktionen:

„Die Technik gibt außerdem noch die Möglichkeit, jung und lebendig zu bleiben. Trotzdem bleiben wir bei aller Begeisterung und aller Leidenschaft mit beiden Beinen auf dem Boden. Die Technik und ihre Gesetze können nicht kommandiert werden. Der Motor ist ein lebendiger Organismus, der mitlaufen muß. Gerade die Technik macht uns feinfühlig. Da wir sie nicht kommandieren, sondern führen, sind wir auf der anderen Seite erst recht in der Lage, menschliche Seelen zu leiten." ${ }^{156}$

Die Metaphern vom „lebendigen Organismus“ des Motors, die eingebauten sozialen Tugenden und das Ziel nach einem höheren Verbreitungsgrad der motorisierten Fortbewegungsmittel entsprachen auch weitgehend den Wunschbildern der nationalsozialistischen Luftfahrtprotagonisten. Reichsluftfahrtminister Göring sah in den Deutschen ein Volk von Fliegern, ${ }^{157}$ und sein Ministerium träumte von der Entwicklung eines „Volksflugzeugs“ ${ }^{158}$ Doch die Forderung „Luftfahrt ist not!" bedeutete nicht, dass jeder „Volksgenosse“ eine Pilotenausbildung absolvieren sollte. Entscheidend war nach Meinung des 1937 wieder gegründeten NSFliegerkorps der ideelle Gehalt dieser Forderung: „Nach jenen schmachvollen Jahren der Wehrlosigkeit soll vielmehr die Idee des Fliegens zum geistigseelischen Gemeingut des deutschen Volkes werden, wie dies symbolisch im Wahrzeichen des NS-Fliegerkorps, dem ,Fliegenden Menschen' zum Ausdruck kommt." 159

Der Aufbau des Kraftfahrwesens, und mehr noch die Entwicklung der Luftfahrt, die bis 1935 den Beschränkungen des Versailler Vertrages unterlag, erschienen in diesem Zusammenhang als Therapeutikum für die gedemütigte Nation.

\section{Werbung für ein "motorisierungsfreundliches" Klima}

Analog zu dem Auftrag an das Nationalsozialistische Fliegerkorps, den „fliegerischen Gedanken im deutschen Volk wachzuhalten", wurde dem NSKK die Aufgabe zugeschrieben, den Motorisierungsgedanken in Deutschland zu wecken und zu beleben. ${ }^{160}$ Nach dem Willen des "Führers" sollte die nationalsozialistische Motorisierungspolitik das Ziel verfolgen, „den Motor für das Volk und das Volk

155 NSKK-Korpsführung (Hrsg.): Dienstfahrzeuge im NSKK.

156 Völkischer Beobachter vom 19. 8. 1939: „Korpsführer Hühnlein auf dem Führer-Appell der NSKK-Motorgruppe Berlin“.

157 Vgl. Görings Maxime: „Ein Volk, das nicht fliegt, ist kein Volk“; zit. nach Jünger (Hrsg.): Luftfahrt ist not!

158 Vgl. Fritzsche: A Nation of Fliers, S. 194.

159 Riehme: Wir fliegen in Wind und Wolken, S. $6 \mathrm{f}$.

160 Vgl. Kehrberg: Vorgeschichte des NS-Fliegerkorps, S. $4 \mathrm{f}$. 
für den Motor zu erobern!“161 Während Hitler den „Motor“ in Form des Volkswagens für das Volk bereitzustellen versprach, war das NSKK beauftragt, das Volk für den Motor zu gewinnen.

Entsprechend der Motorisierungs-Mission schufen die Korps-Propagandisten ein neues Erziehungsideal für Deutschland: den „Aufbau eines motorbejahenden neuen Volkes auf neuen Straßen ". ${ }^{162}$ Neben der nationalsozialistischen Presse und der staatlichen Gesetzgebung sollte das NSKK als dritte Säule an diesem Aufbau beteiligt sein. In einem Korpsbefehl von 1935 definierte der Korpsführer: „Das NSKK verkörpert die motorisierte Kraft der Partei und ist der Banner- und Willensträger des Motorisierungsgedankens der deutschen Nation." ${ }^{163}$ Die Titulierung als „Banner- und Willensträger der Motorisierung“ ist die am häufigsten wiederholte Selbst- und Fremdbeschreibung des NSKK. ${ }^{164}$ Sie wies ihm die Rolle eines Werbeträgers der Motorisierung zu. Die Korpsführung warb vor allem für ein Umdenken innerhalb der Bevölkerung: „Die volksschädliche Einstellung gegenüber dem Kraftfahrzeug muß überwunden - die Leistungsfähigkeit der deutschen Kraftfahrzeugindustrie gesteigert - Verständnis und Begeisterung für den Motor in das Volk, besonders in die Jugend hineingetragen werden. "165

Das NSKK nannte sich auch „Vorkämpfer“ der Motorisierung 166 - eine Bezeichnung, die bisher für die Erfinder und Konstrukteure des Kraftwagens sowie für die Automobilclubs in der Frühzeit der Automobilisierung reserviert war. Verständlich wird diese Definition aus einer spezifisch nationalsozialistischen Sicht auf die Automobilgeschichte. Die Nationalsozialisten pflegten den Mythos von der Kraftverkehrsfeindschaft der Weimarer Regierungen, die das Volk mit ihrem "Autohass" infiziert und mit kraftverkehrsfeindlichen Gesetzen und Meinungsäußerungen überschwemmt habe. ${ }^{167}$ Die NS-Propaganda verbreitete den Eindruck, das Volk, das ja eigentlich offen sei für technische Errungenschaften, sei durch die kraftfahrfeindlichen Regierungen um sein automobiles Anrecht gebracht worden.

$\mathrm{Zu}$ fragen ist, ob die Grundannahme einer „Verkehrsfeindlichkeit“ der Weimarer Republik richtig war. Reagierten weite Teile der deutschen Bevölkerung tatsächlich ablehnend auf das Kraftfahrzeug und kann die Verkehrspolitik in dieser Zeit als Motorisierungshindernis bezeichnet werden? Ein Blick auf den Straßenverkehr der ersten 30 Jahre des 20. Jahrhunderts gibt darüber Aufschluss.

Als das Kraftfahrzeug den öffentlichen Raum zu dominieren begann, veränderte sich die Verkehrssituation zu Ungunsten derjenigen, die nicht motorisiert waren.

161 Oppermann: Unter den Sturmstandern, S. 113.

162 Ebenda, S. 89.

163 Korpsbefehl Nr. 12a vom 25. 7. 1935, BArch NSD 42/9.

164 „Wie stets, schuf sich der Führer auch in diesem Falle eine organisierte lebendige Kraft als Banner- und Willensträger der Motorisierung“; NSKK-Korpsführung (Hrsg.): NSKK, S. 4 f. Vgl. auch: NSKK-Korpsführung (Hrsg.): Die Gliederung des NSKK, S. 2.

165 NSKK-Korpsführung (Hrsg.): NSKK, S. 4.

166 Ebenda, S. 5.

167 Die Berliner Börsen-Zeitung weist diese Behauptung zurück. Feindschaft habe es nur zu Beginn des Automobilismus gegeben; vgl. Hermann: Kraftverkehrsfeindschaft? Nein!, S. 6 . 
Von einem Ort der Kommunikation wurde die Straße auf die Funktion einer Fahrbahn reduziert. Das mitunter militante Aufbegehren der benachteiligten Verkehrsteilnehmer und Anwohner in der Frühphase des Autos zu Beginn des 20. Jahrhunderts war eine Reaktion auf die negativen Begleitumstände des motorisierten Verkehrs: Lärm, Gestank und Unfälle. ${ }^{168}$ Der Protest nahm in den zwanziger Jahren fühlbar ab, als Verhaltensregeln konfliktträchtige Situationen entschärften, die Fahrzeuge sicherer wurden und eine gewisse Gewöhnung an motorisiertes Verkehrsleben eintrat. Zudem wurde das Image des Kraftfahrzeugs durch die Popularität des Motorsports und die Werbung der Automobilclubs verbessert. 169

Die Politik der Regierungen der Weimarer Republik gegenüber dem Kraftfahrzeug kann als zurückhaltend charakterisiert werden. Finanzpolitische Erwägungen bestimmten die Bemühungen, Schaden von der Eisenbahn abzuwenden, über Ausgleichszahlungen die deutsche Landwirtschaft zu stabilisieren und durch hohe Kraftfahrzeugsteuern und Benzinzölle Einnahmen zu erzielen. ${ }^{770}$ Außerdem hielt der Reichsetat nur wenig Geld für den Bau und die Instandhaltung von Straßen bereit. Man kam dem Motorisierungswillen der Bevölkerung jedoch entgegen, indem man Krafträder bis $250 \mathrm{ccm}$ steuerfrei beließ. In Bezug auf diese Verkehrspolitik von „Autohass“ zu sprechen, wie es die Nationalsozialisten taten, war eine bewusste Übertreibung. Die Gründe für die schlechte Situation des Kraftfahrwesens waren nicht nur verkehrspolitischer, sondern auch struktureller Art. $\mathrm{Zu}$ viele Unternehmen bauten zu teure Wagen in zu vielen unterschiedlichen Ausführungen. Die Standardisierung der Herstellung hatte sich bei der Mehrzahl der Autobauer im Produktionsablauf noch nicht durchgesetzt. Dies wirkte einer Verbilligung des Kaufpreises entgegen. ${ }^{171}$ Ein wichtiger Grund dafür, dass das Auto noch immer in der Kategorie Luxusgefährt verharrte, war in den Auswirkungen der Weltwirtschaftskrise zu finden, die Produzenten und Kunden schwer belastete. ${ }^{172}$

Festzustellen bleibt jedoch, dass der grundsätzliche Innovationswiderstand gegen den motorisierten Individualverkehr Anfang der dreißiger Jahre in der Bevöl-

168 Merki: Die ,Auto-Wildlinge` und das Recht, S. 51. Vgl. zur Kritik am Automobil zu Beginn des 20. Jahrhunderts Haubner: Nervenkitzel und Freizeitvergnügen, S. 156-164. Akzeptanzschwierigkeiten hatten um 1900 vor allem die Landbevölkerung und das Bildungs- und Kleinbürgertum. Die fortschrittsoptimistischen Linksliberalen und Vertreter der Arbeiterschaft sahen die Entwicklung und Verbreitung des Automobils als Fortschritt, weil sie auf einen industriellen Aufschwung hofften; vgl. Diehl: Tyrannen der Landstraße, S. 51-57.

169 Vgl. Diehl: Tyrannen der Landstraße, S. 52

170 Die Treibstoffzölle für Benzin wurden 1930 von 6 auf 10 RM je Doppelzentner erhöht. Zusammen mit der Verordnung über die Abnahmepflicht von preisgebundenem Spiritus vom Juli 1930 verteuerten sich die Haltungskosten; vgl. Edelmann: Vom Luxusgut, S. 130.

171 Dies wurde zu Beginn des Jahres 1933 von einigen Publizisten kritisiert; vgl. Bottke: Reichshilfe für die Kraftverkehrswirtschaft?; Hermann: Kraftverkehrsfeindschaft? Nein!

172 Auch eine 1933 entstandene Dissertation findet die Gründe für den verminderten Kraftfahrzeugabsatz in Deutschland nicht im „Autohass“, sondern in anderen Faktoren: Wirtschaftskrisen, Strukturen in der Autoindustrie, begrenzte Kaufkraft der Bevölkerung, Überkapazitäten des Marktes; vgl. Kurt Schneider: Die Hauptprobleme des Kraftfahrzeugabsatzes in Deutschland, S. 102, 131. 
kerung bereits gebrochen war. Es bestand kein Zweifel mehr daran, dass sich die Technik des Verbrennungsmotors durchgesetzt hatte und die Motorisierung des Verkehrs unaufhaltsam voranschritt. Das Gespenst von der „Autofeindschaft“ im Volk war ein Phantom, das von Hitler, Goebbels und Hühnlein bewusst eingesetzt wurde, um die NS-Motorisierungspolitik in einem glanzvolleren Licht zu präsentieren. Da der Kauf und der Massenbesitz von Kraftfahrzeugen politisch erwünscht war, warben die NS-Machthaber für ein "motorbejahendes Volk“. Auch wenn ein Großteil der Bevölkerung bereits motorbejahend eingestellt war, kann mit gutem Grund angenommen werden, dass durch das Versprechen des Volkswagens, durch den Bau neuer Straßen, durch die Förderung des Motorsports und durch eine Reihe weiterer Maßnahmen die Motorbegeisterung der „Volksgenossen“ einen neuen Schub erhielt. Den Autobesitz für Mittelschichtskreise in Aussicht zu stellen, erhöhte in jedem Fall die Akzeptanz der individuellen motorisierten Fortbewegung. Ein Durchbruch allerdings wäre erst mit der Realisierung der Motorisierungswünsche erzielt worden.

\section{„Werbestrategien“ des NSKK}

Um Begeisterung für das Kraftfahrzeug zu wecken, setzte das NSKK vor allem propagandistische Mittel ein. Politische Aufmärsche sollten der Bevölkerung die Motorisierung näher bringen. Motor-SA und NSKK veranstalteten 1933 unzählige Versammlungen und Triumphzüge: ${ }^{173}$ Am 7. Mai 1933 traten in Kiel 2000 Motor-SA-Männer mit 1412 Fahrzeugen an ${ }^{174}$, am 25. Juni 1933 fand das Gruppenstaffeltreffen der motorisierten SA und des NSKK im Kölner Stadion mit 6000 Kraftfahrzeugen statt ${ }^{175}$, am 9. Juli 1933 trafen sich 4000 motorisierte Nationalsozialisten in Dortmund ${ }^{176}$ und am 7./8. Oktober veranstalteten 10000 MotorSA-Männer in Schlesien einen Aufmarsch. ${ }^{177}$ "In jenen Monaten wurde Millionen Volksgenossen infolge solcher und anderer NSKK-Veranstaltungen stärker als zuvor der Gedanke der Motorisierung Deutschlands nahe gebracht!" 178 , so der Kommentar des NSKK-Chronisten Theodor Oppermann. Da die motorisierten Verbände der SA Hakenkreuzfahnen und keine Banner mit "Ja zur Motorisierung " oder ähnlichen Werbeslogans hochhielten, dürfte diese Argumentation auch den Gutgläubigsten nicht überzeugt haben. Der Zweck der Aufzüge 1933 lag darin, Siegesgefühle auszukosten, Stärke zu demonstrieren und den politischen Gegner einzuschüchtern.

Dennoch gab sich die Korpsführung davon überzeugt, dass die Werbearbeit für den Motor Früchte getragen habe, denn im März 1939 resümierte „Der NSKKMann“:

173 Oppermann: Unter den Sturmstandern, S. 105-110.

174 Deutsche Kraftfahrt vom 15. 6. 1933: „Der Kieler Hitlertag“.

175 Vgl. Westdeutscher Sport-Beobachter vom 26. 6. 1933: „Großer Tag der Motor-SA und des NSKK".

176 Vgl. Deutsche Kraftfahrt vom 15. 7. 1933: „Dortmund im Zeichen des Sturzhelms“.

177 Oppermann: Unter den Sturmstandern, S. $108 \mathrm{f}$.

178 Ebenda, S. 108. 
„So aber trug das Korps mit seinen Aufmärschen, mit seinen Kundgebungen, mit seinen kraftfahrsportlichen Veranstaltungen, mit der ganzen ungeheuerlichen Kleinarbeit seiner Einheiten und Männer zuerst einmal die Idee der Motorisierung ins Volk. Es weckte das Interesse, dann die Freude und schließlich den Willen zum Motor und schuf so die psychologische Voraussetzung für das, was nun durch die Maßnahmen des Staates unterstützt wurde." 179

Auch die zweite vom NSKK eingeschlagene Werbestrategie kann nicht als Werbung im eigentlichen Sinn verstanden werden. Mit der von oben oktroyierten Motorisierungsfreundlichkeit veränderte sich der öffentliche Diskurs für und wider die Motorisierung. Wer Motorisierung auch nach dem Anbruch des „Dritten Reiches" noch kritisch betrachtete, wurde gewarnt: „Verkehrsfeinde sind Volksfeinde!", so die Artikelüberschrift im „NSKK-Mann“ vom 12. Februar 1938, die deutlich aufzeigte, wo die Grenze zwischen Freund und Feind verlief.

Das NSKK selbst nahm oft und leidenschaftlich Partei für die Motorisierung. Alles, was dem Leitbild eines motorbejahenden Volkes widersprach oder nur den Anschein einer Kritik in sich barg, wurde vom NSKK publizistisch niedergerungen: Besinnliche Gedanken in einem Sonntagsblatt, dessen Verfasser auf der Autobahn in eine melancholische Stimmung fiel, verurteilte das NSKK als Verunglimpfung der „schönsten Straßen der Welt“180; die Reichsverkehrsgruppe Schienenbahnen, die die volkswirtschaftlichen Schäden einer ungehemmten Entwicklung des Kraftfahrzeugverkehrs beklagte, wurde darüber belehrt, dass der Schutz der Kleinbahnen geringer zu bewerten sei als die große Aufgabe der Motorisierung. ${ }^{181}$ Die Tatsache, dass immer noch Bücher im Handel waren, die im Auto keinen Kulturfortschritt erkannten, sah das NSKK als Skandal an. ${ }^{182}$ Die Technikakzeptanz zu fördern hieß nach NSKK-Lesart, jegliche Kritik am Motorisierungsprogramm und den daraus resultierenden Folgen zu unterdrücken.

Da das NSKK nicht nur Aufgaben für die SA und die Partei übernahm, sondern sich im Sommer 1934 als nunmehr selbständige Gliederung profilieren wollte, war der „Kampf um die Motorisierung Deutschlands“ ein willkommener Auftrag, um aus dem politischen Nischendasein auszubrechen. Mit der Bezeichnung „Willensträger der Motorisierung" stattete sich das NSKK mit einem Titel aus, der ihm als Legitimationsgrundlage für seinen gesamten gesellschaftlichen Zielkatalog diente. Dieser Titel war die Begründung für den Führungsanspruch im Motorsport, bei der Fusion der Automobilclubs und in der Verkehrserziehung. Ein weiterer Grund für die häufige Verwendung der Bezeichnung „Banner- und Willensträger der Motorisierung" liegt darin, dass dem NSKK wichtige Kompetenzen durch den „Führer“ versagt blieben. Die wirtschaftspolitischen Forderungen, die das NSKK vor und nach der Machtübernahme erhob, wie die Förderung deutscher Arbeitsstätten, Verbilligung der Fahrzeughaltung, Durchführung eines Straßenbauplans, lagen außerhalb des Wirkungsbereichs des NSKK. ${ }^{183}$ Das NSKK be-

179 Der NSKK-Mann vom 11. 3. 1939: „Wofür kämpfen wir?“

180 Vgl. Der NSKK-Mann vom 28. 1. 1939: „Autobahn bringt Sterbegedanken?“

181 Vgl. Der NSKK-Mann vom 7. 5. 1938: „Verkehrs- und Kleinbahnwünsche“.

182 Vgl. Der NSKK-Mann vom 15. 10. 1938: „Die Autotollwut“.

183 Zu den wirtschaftspolitischen Zielen vor und knapp nach der Machtübernahme vgl. die Werbebroschüre von 1933: „Jeder deutsche Autofahrer und deutsche Motorradfahrer ge- 
fasste sich folglich nicht mit der praktischen Lösung der Motorisierungsprobleme, sondern sah sein Einsatzgebiet vorrangig im ideellen und atmosphärischen Bereich. Den Motorisierungsgedanken in die Tat umzusetzen war der Industrie, den Behörden, der DAF und dem Generalinspektor für das deutsche Straßenwesen vorbehalten.

Wie an den „Werbestrategien“ erkennbar ist, ging es weniger darum, der Bevölkerung die motorisierte Fortbewegung als Spaßfaktor und Freizeitaktivität näher zu bringen. Vorrangiges Ziel des „Banner- und Willensträgers der Motorisierung“ war die ideologische Ausrichtung und Gleichschaltung der Kraftfahrer und Motorisierungswilligen. Die Deutschen sollten sich unter Anleitung des NSKK zu einem motorbejahenden Volk entwickeln, das das sportliche, wirtschaftliche und militärische Potenzial des Motors zu nutzen wusste.

\section{Die nationalsozialistische Motorisierungspolitik - modern, antimodern oder Ausdruck einer Modernisierungs- diktatur?}

Der Soziologe Ralf Dahrendorf und der Historiker David Schoenbaum entfachten Ende der sechziger Jahre eine bis heute anhaltende Kontroverse über das Verhältnis von Nationalsozialismus und Modernisierung. Sie diagnostizierten einen sozialrevolutionären "Stoß in die Modernität“, der ein ungewolltes Ergebnis nationalsozialistischer Politik gewesen sei und weder den Absichten Hitlers noch dem Inhalt der NS-Ideologie entsprochen habe. ${ }^{184}$ Henry A. Turner vertrat in seinem 1972 erschienenen Aufsatz „Fascism and Modernization“ ebenfalls die Meinung, dass die Nationalsozialisten ihre antimodernen Utopien mit den Mitteln einer hoch industrialisierten Gesellschaft umsetzen wollten. Ihr eigentliches Ziel sei jedoch die nach Osten gerichtete Lebensraum- und Siedlungspolitik gewesen. Mit Betonung auf Hitlers Weltanschauung vor 1933 charakterisierte Turner den Nationalsozialismus als „Ausdruck utopischen Anti-Modernismus“185.

Einige Historiker, die zu Beginn der neunziger Jahre in ihren Arbeiten dieses Thema aufgegriffen haben, darunter Michael Prinz, Rainer Zitelmann und Ronald Smelser, sprachen dem Nationalsozialismus dagegen eine intentionale Modernisierungswirkung zu. ${ }^{186}$ Seither diskutiert die historische Forschung die Frage nach den „modernen“ Elementen der NS-Ideologie und prüft, ob eine „Revolution " in Richtung eines technokratisch geführten, sozialpolitisch organisierten Industriestaates zwischen 1933 und 1945 beabsichtigt war bzw. überhaupt stattge-

hört ins Nationalsozialistische Kraftfahr-Korps (NSKK)“; Völkischer Beobachter vom 6. 4. 1933: „Drei Jahre NSKK“; Deutscher Sport vom 19. 5. 1933 „NSKK“.

184 Vgl. Dahrendorf: Gesellschaft und Demokratie in Deutschland; Schoenbaum: Die braune Revolution.

185 Turner: Faschismus und Anti-Modernismus, S. 169.

186 Vgl. Smelser: Robert Ley; Zitelmann: Hitler; Zitelmann u.a. (Hrsg.): Nationalsozialismus und Modernisierung. 
funden hat. ${ }^{187}$ Von der definitorischen Unschärfe des Begriffs Modernisierung ${ }^{188}$ und anderen Vorbehalten abgesehen, bezweifeln nicht wenige Forscher, ob es überhaupt Sinn macht, eine humanitätsfeindliche Ideologie daraufhin zu befragen, ob sie "modern" sei. 189

An diese Fragen anknüpfend steht im Folgenden der Erfolg der Motorisierungsmaßnahmen, gemessen an der sozioökonomischen Entwicklung, auf dem Prüfstand. Daran anschließend wird der Stellenwert der Motorisierungspolitik im gesamten NS-Ideologiegebäude beurteilt und untersucht, inwiefern die Analyseraster "modern" und "antimodern“ Kategorien sein können, die die nationalsozialistische Politik in diesem Bereich adäquat beschreiben.

\section{Die Frage nach der sozioökonomischen Modernisierungsleistung}

Will man die Erfolge des Motorisierungsprogramms nach industriegesellschaftlichen Wachstumskriterien beurteilen, sind die Maßnahmen der Hitler-Regierung daran zu messen, in welchem Umfang sie wirksame Prozesse in Richtung gesteigerter Wachstumsdynamik und sozialer Inklusion größerer Bevölkerungskreise bewirkten. ${ }^{190} \mathrm{Um}$ die zwei genannten Modernisierungsmerkmale im Zusammenhang mit der Motorisierungspolitik untersuchen zu können, ist es sinnvoll, eine umfassende Definition von Motorisierung zugrunde zu legen. Motorisierung, so der Volkswirtschaftler Rainer Willeke, bezeichnet den

„fortschreitenden Einsatz des Verbrennungsmotors als Antrieb für Verkehrsmittel. Motorisierung verstärkt die Dynamik von Differenzierung und Individualisierung, und zwar gleichermaßen in Richtung auf eine expansiv aufgefächerte Produktionsentwicklung und auf eine durch den Mobilitätsgewinn geprägte neuartige Lebens- und Konsumgestaltung." 191

Das Tempo und der Umfang der Motorisierung lassen sich an der Entwicklung des Kraftfahrzeugbestandes ablesen. Jedoch ist es aufgrund einer so kurzen Periode, wie sie die sechs Jahre zwischen 1933 und 1939 darstellen, erkenntnistheoretisch problematisch, die Ursachen für Wandlungsprozesse auf ein bestimmtes politisches Programm zurückzuführen. Dies bedeutet, dass die Wirkung national-

187 Vgl. zur „Modernisierungsdebatte“ die Beiträge von Könke: „Modernisierungsschub“ oder relative Stagnation?; Herf: Der nationalsozialistische Technikdiskurs, S. 72-93; Rabinbach: Nationalsozialismus und Moderne; Roth: Historisierung des Nationalsozialismus?, S. 31-52.

188 Grundsätzliche Überlegungen zur Anwendbarkeit von Modernisierungstheorien in der Geschichtswissenschaft und zu deren Definierung: Wehler: Modernisierungstheorie und Geschichte, S. 59. Für die Soziologie: Lepsius: Soziologische Theoreme über die Sozialstruktur der „Moderne“ und die „Modernisierung“, S. $12 \mathrm{ff}$; Matzerath u. a.: Modernisierungstheorie und Nationalsozialismus, S. 102; Peukert: Die Weimarer Republik, S. $11,87 \mathrm{ff}$.

189 Vgl. Messerschmidt: Nationalsozialismus und Stalinismus. Auch Hans Mommsen warnte davor, der NS-Politik „nachträglich positive Züge an[zu]dichten“; Mommsen: Noch einmal: Nationalsozialismus und Modernisierung, S. 399.

190 Nach der Kriterienbildung von Alber: Nationalsozialismus und Modernisierung, S. 346387.

191 Willeke: Motorisierung und Volkswirtschaft, S. 17. 
sozialistischer Förderungsmaßnahmen von der wirtschaftlichen Erholungsphase nach der Weltwirtschaftskrise nicht eindeutig getrennt werden kann.

Der nach dem Ende der Weltwirtschaftskrise eingetretene Preissturz bei Kraftfahrzeugen verursachte schon im ersten Quartal des Jahres 1933 eine spürbare Belebung auf dem Inlandsmarkt. Die nationalsozialistischen Maßnahmen zur Steuererleichterung für Kraftfahrzeughalter und zur Verbesserung der Infrastruktur wirkten absatzfördernd. In der Forschung werden sie gemeinhin als „Initialzünder" für die anschließend beachtlichen Absatzsteigerungen angesehen. ${ }^{192}$ Die Konjunktur auf dem Kraftfahrzeugmarkt hatte auch positive Effekte auf die Zahl der Beschäftigten in der Automobil- und Zubehörindustrie.

Hitler glaubte, seine Politik könne den Verbreitungsgrad des Autos erhöhen. In einer Besprechung mit Industriellen am 29. Mai 1933 hatte er angekündigt, den Bestand an Personenwagen in Deutschland um drei bis vier Millionen zu steigern, drei Jahre später gab er als Ziel aus, insgesamt einen Pkw-Bestand von drei bis vier Millionen erreichen zu wollen. ${ }^{193}$ Wie aus der folgenden Tabelle über die Entwicklung des Kraftfahrzeugbestandes zwischen 1933 und 1939 ersichtlich wird, erreichte Hitler diese Zielvorgabe nicht einmal annähernd:

Der Kraftfabrzeugbestand in Deutschland 1933-1939, jeweils am Jabresanfang:194

\begin{tabular}{lccc}
\hline & $\begin{array}{l}\text { Motorräder, } \\
\text { inkl. Kleinkrafträder }\end{array}$ & Personenwagen & $\begin{array}{l}\text { Kraftfahrzeuge } \\
\text { (insgesamt) }\end{array}$ \\
\hline 1933 & 866017 & 561042 & 1633297 \\
1934 & 894042 & 580987 & 1682985 \\
1935 & 983994 & 674523 & 1887632 \\
1936 & 1058656 & 809727 & 2157811 \\
1937 & 1184081 & 945085 & 2474591 \\
1938 & 1327189 & 1108433 & 2848466 \\
1939 & 1582872 & 1305608 & 3364503 \\
\hline
\end{tabular}

Der Zuwachs an Personenkraftwagen zwischen 1933 und 1939 von 0,5 auf 1,3 Millionen blieb um $50 \%$ hinter der Zielmarke zurück. Insgesamt gesehen war eine grundlegende Veränderung der Verkehrssituation mit einem Kraftfahrzeugbestand von rund 3,5 Millionen Fahrzeugen in Deutschland nicht zu erreichen, auch wenn damit die Basis für eine langfristige Entwicklung gelegt wurde. ${ }^{195}$

192 Vgl. Edelmann: Vom Luxusgut, S. 161; Henning: Kraftfahrzeugindustrie und Autobahn in der Wirtschaftspolitik 1933-1936, S. 224-230; Braun: Anfänge der Massenmotorisierung, S. 114.

193 Vgl. Ludwig: Technik und Ingenieure im Dritten Reich, S. 318; RDA (Hrsg.): „Schrittmacher der Wirtschaft", S. $15 \mathrm{f}$.

194 Quelle: Motorschau vom Februar 1940.

195 Von „Massenmotorisierung“ sprechen Experten erst seit dem beschleunigten Anstieg der zugelassenen Autos in der zweiten Hälfte der fünfziger Jahre. Vgl. für das Gebiet der 
Nicht nur Anspruch und Wirklichkeit der Wachstumspolitik lagen weit auseinander, auch der Rückstand zu den anderen westlichen Industriestaaten verringerte sich nur wenig. Die Vorsprünge der anderen europäischen Industrienationen konnten nicht aufgeholt werden. Deutschland erreichte 1936 das automobile Niveau, auf dem sich Großbritannien zehn Jahre früher bewegt hatte. ${ }^{196}$ In Deutschland kam 1938 ein Auto auf 51 Einwohner, in Frankreich betrug das Verhältnis $1 \mathrm{zu} 23$ und in Großbritannien $1 \mathrm{zu} 24 .{ }^{197}$

Historische Studien von Karl-Heinz Ludwig und Heidrun Edelmann konstatieren eine politisch initiierte Konjunkturbelebung, die für eine Steigerung des Kraftfahrzeugbestandes verantwortlich gemacht werden kann. Doch angesichts des deutschen Nachholbedarfs und real vorhandener Wachstumsmöglichkeiten sieht die Forschung hierin nicht den durchschlagenden „Erfolg“ einer Politik, die in medienwirksamer Weise die „Motorisierung des Volkes" angekündigt hatte. ${ }^{198}$

Die Mehrheit der Deutschen konnte die Kosten für den Führerscheinerwerb, die Anschaffung eines Autos und die dafür notwendigen Unterhalts- und Betriebskosten nicht aufbringen. Der vorhandene „Motorisierungswille“ in Deutschland konzentrierte sich in den zwanziger und dreißiger Jahren auf das Motorrad. ${ }^{199}$ Deutschland hatte den höchsten Bestand an Motorrädern und entwickelte sich zum führenden Produzenten von Motorrädern. ${ }^{200}$

Die Bezeichnung des Kraftwagens als „Gebrauchsartikel“ blieb eine Floskel, da sich die Einkommensverhältnisse zwischen 1933 und 1939 nicht grundlegend verbesserten und das staatlich subventionierte Volkswagenprojekt nicht realisiert wurde. ${ }^{201}$ Motorisierungshemmend wirkte sich zudem die NS-Treibstoffpolitik aus. Das Autarkiekonzept stand von Anfang an in einem latenten Widerspruch zum zivilen Motorisierungsprogramm. Nach Inkrafttreten des Vierjahresplans

Bundesrepublik Deutschland: 1957: 2320000; 1959: 3374000; 1961: 4856000 ; Ruppert: Das Auto, S. 126.

$1961932 \mathrm{kam}$ auf 135 Einwohner, 1936 auf 71 Einwohner ein Automobil. Dies entsprach dem Niveau, das Großbritannien zehn Jahre zuvor hatte. 1936 kam dort ein Auto auf 26 Einwohner; Edelmann: Vom Luxusgut, S. 167.

197 Vgl. Braun: Anfänge der Massenmotorisierung, S. 115.

198 Vgl. Ludwig: Technik und Ingenieure im Dritten Reich, S. 318 f.; Bavay: Die Ambivalenz der Moderne, S. 145. Auch Kopper kommt zu dem Schluss, dass die Motorisierungspolitik hinter ihren Möglichkeiten zurückblieb; Kopper: Modernität oder Scheinmodernität?, S. 409.

$199 \mathrm{Zu}$ Beginn der dreißiger Jahre besaß Deutschland knapp 1/3 des Weltbestandes an Motorrädern und nur $2 \%$ des Weltbestandes an Autos. Für den Unterhalt eines Autos war Anfang der dreißiger Jahre ein Bruttojahresgehalt von mindestens $8000 \mathrm{RM}$ nötig. Dies entsprach dem Vierfachen eines Arbeitereinkommens und wurde nur von $2 \%$ der Bevölkerung erreicht; Gömmel: Technik und Mobilität, S. 304 f.; Betz: Das Volksauto, S. 42.

2001938 waren 1,5 Mio. Motorräder in Deutschland zugelassen, in Großbritannien (mit Nordirland) sank die Zahl 1938 auf 466000 und in Frankreich stagnierte sie bei 530000; Tatsachen und Zahlen der Kraftverkehrswirtschaft 1938, hrsg. vom Reichsverband der Automobilindustrie Berlin 1939, S. 118. 1936 produzierte Deutschland 160000 Krafträder, 1938 waren es sogar 327500. Großbritannien produzierte 193665000 und 1938 67000 Motorräder; Reichsverband der Automobilindustrie: Tatsachen und Zahlen der Kraftverkehrswirtschaft 1937, S. 166 und Tatsachen und Zahlen der Kraftverkehrswirtschaft 1938, S. 127.

201 Vgl. Edelmann: Vom Luxusgut, S. 237 f. 
1936 traten die Zielkonflikte zwischen der Erhöhung des Kraftfahrzeugbestandes zur privaten Nutzung und der Materialkontingentierung und Rohstoffzuweisung im Rahmen der Aufrüstung noch deutlicher zu Tage. Die Konstituierung eines Rohstoff- und Devisenstabes unter der Leitung von Hermann Göring stellte 1936 die Weichen für den umfassenden Aufbau einer nationalen Treibstoffindustrie. Das industriell betriebene Verfahren zur Kohlehydrierung war unter volkswirtschaftlichen Gesichtspunkten unrentabel, aus rüstungspolitischen Gründen aber notwendig. ${ }^{202}$ Mit Inkrafttreten des Vierjahresplans 1936 wurde die Motorisierungspolitik de facto den Rüstungszielen untergeordnet. Auch andere technische Entwicklungen, den privaten Bereich betreffend wie z.B. die Elektrifizierung der deutschen Haushalte, wurden zugunsten der Rüstungspolitik abgebrochen. ${ }^{203}$

Zieht man eine Gesamtbilanz der nationalsozialistischen Motorisierungspolitik, kann festgestellt werden, dass die Realität weit hinter dem propagandistischen Anspruch zurückblieb und kein weitreichender Mobilitätsgewinn erzielt wurde, der eine neuartige Konsumorientierung und Freizeitkultur hätte begründen können. Der entscheidende Modernisierungsstoß in Richtung "Massenmotorisierung" und Mobilitätssteigerung erfolgte nicht in der NS-Zeit, sondern in den sechziger Jahren der Bundesrepublik. ${ }^{204}$

\section{Die Verschränkung moderner und antimoderner Elemente in der NS-Ideologie}

Untersucht man einen einzelnen Teilbereich nationalsozialistischer Politik, wie hier die Motorisierungspolitik, auf seine „Modernität“, ist es notwendig zu betonen, dass es sich dabei um ein Mosaiksteinchen im gesamten Ideologiegebäude und um ein Ziel unter anderen handelte. Wie im oberen Teil deutlich wurde, strebte das Regime in der Verkehrspolitik einen Modernisierungseffekt an, der zwar keinen nachhaltigen Erfolg erzielte, jedoch als ernsthafter Versuch gewertet werden muss, Deutschland in ein motorisiertes Zeitalter zu führen. Darauf weisen sowohl die in diesem Politikfeld als Qualitätsmerkmale verwendeten Attribute "modern“, „fortschrittlich“ und "freiheitlich" hin als auch Hitlers stadtplanerische Utopien für die Zeit nach dem „Endsieg“. Darin brachte er seine Siedlungspläne mit der Motorisierung in Einklang. Er träumte im Oktober 1941 laut vom Bau einer Autobahn an die Südspitze der Krim: „an diese Verkehrsstränge reihen sich, wie an eine Perlenschnur, die deutschen Städte [...]. “ Den russischen Einwohnern der Städte gegenüber hätten die Deutschen keine Verpflichtungen. Hitler wies den Russen im Verkehrsleben eine Fußgängerrolle zu: „und im übrigen sollen sie nur die Verkehrszeichen kennen, damit sie uns nicht in die Wagen laufen."205

202 Vgl. ebenda, S. 180-184.

203 Der volltechnisierte Haushalt, in dessen Mitte der "Volkskühlschrank“ thront, blieb ein Propagandaideal; vgl. Keßler: „Elektrische Helfer“ für Hausfrau, Volk und Vaterland.

204 Vgl. Ruppert: Das Auto, S. 128.

205 Aufzeichnung vom 17. 10. 1941, in: Jochmann (Hrsg.): Adolf Hitler. Monologe im Führer-Hauptquartier 1941-1944, S. 90 f. Auch dem Volkswagenprojekt blieb Hitler in Kriegszeiten gedanklich verbunden. Er begrüßte im April 1942 die kriegsbedingte Normung im Motorenbereich, da ein Einheitsmotor die Herstellung von Autos in Zukunft verbilligen könnte und sie dann auch für Fabrikarbeiter erschwinglich würden; vgl. Auf- 
Das nationalsozialistische Motorisierungsprogramm war ohne Zweifel mehr als ein propagandistischer Rattenfängertrick zur Sympathiewerbung. Die meisten Historiker stimmen mittlerweile der These zu, dass Hitler ein überzeugter, kein vorgetäuschter Befürworter der modernen Technik- und Industriegesellschaft war und die NS-Ideologie allein schon aufgrund ihrer Heterogenität nicht als „atechnische Blut- und Bodenideologie“ typisiert werden kann. ${ }^{206}$ Auch der ideologische Einsatz des NSKK für die Konsistenz und Verbreitung der NS-Motorisierungsideologie - das Werben für Motorbegeisterung und die vielfältigen Anstrengungen, mittels sprachlicher Konstrukte die Technik mit der Natur zu versöhnen und in das deutsche Kulturerbe einzubetten - steht für eine radikale Absage an rückwärts gewandte Agrarutopien. Motorisierung und Industrieentwicklung im „Dritten Reich“ können als Belege dafür gelten, dass sich politische Diktatur und industrielle Moderne miteinander vereinbaren lassen. ${ }^{207}$

Über die neue Verkehrs- und Kommunikationstechnologie wurden Kraftfahrzeuge, Panzer, Flugzeuge, Rundfunk und Film zu neuen Herrschaftsmitteln, die im Verbund mit einer politischen Ideologie große Möglichkeiten zur Machtkonsolidierung, Machterweiterung und militärischen Machtausübung in Aussicht stellten. ${ }^{208}$ Dieses Denken lässt sich auch bei den nationalsozialistischen Luftfahrt-Propagandisten finden, die der Historiker Fritzsche in seinem Buch „A Nation of Fliers" beschreibt: „Nazis and other nationalists thought about airplanes because they thought about Germany's future prosperity in terms of mobilization of technology, authority and public loyality. “209

Die „Antimodernität“ des nationalsozialistischen Regimes bestand nicht darin, vorindustrielle Zustände anzustreben. „Antimodern" war der Nationalsozialismus in seiner "rassisch-völkischen" Technologiebegründung und in seinem allumfassenden Glauben an die Überlegenheit der "arischen Rasse“. Die „Liebe zur Scholle" und die "Liebe zur Technik" hatten ihren gemeinsamen Bezugspunkt in der „arischen Volksgemeinschaft“ und der rassenimperialistischen Machtentfaltung Deutschlands.

In Ideologie und Praxis der Motorisierungspolitik verband sich technologischer Fortschritt mit kultureller Regression. Dies war Ausdruck einer Weltanschauung, in der es keinen Widerspruch, sondern eine Verbindung von modernen und antimodernen Elementen gab: „His [Hitlers] embrace of modern technology as an expression of Aryan will was fully consonant with rejection of the Enlightenment and the social consequences of the French and industrial revoluti-

zeichnung vom 9. 4. 1942, in: Picker (Hrsg.): Hitlers Tischgespräche im Führerhauptquartier, S. 207.

206 Walker u. a.: Technikdiskurs und Technikideologie im Nationalsozialismus, S. 430.

$207 \mathrm{Vgl}$. auch Hachtmann: „Die Begründer der amerikanischen Technik sind fast lauter schwäbisch-alemannische Menschen“, S. 65.

208 Die Verbindung von Politik und Technik trat in Leni Riefenstahls Film „Triumph des Willens" deutlich hervor. Das Flugzeug JU 52 wurde als Herrschaftsinstrument eines politischen Systems inszeniert; Asendorf: Super Constellation - Flugzeug und Raumrevolution, S. 91.

209 Fritzsche: A Nation of Fliers, S. 215. 
ons“, so urteilt Jeffrey Herf in seinem Buch „Reactionary Modernism“.210 Dem Autor kommt das Verdienst zu, mit diesem Titel, der zum Schlagwort avancierte, das scheinbar Paradoxe dieser Verbindung auf den Punkt gebracht zu haben: „The paradox of reactionary modernism is that it rejected reason but embraced technology, reconciled Innerlichkeit with technical modernity. “211

Die der Aussage zugrunde liegende Prämisse, dass die Ablehnung der Werte der französischen Revolution ein Zeichen von Antimodernität sei, blieb nicht unwidersprochen. Beispielhaft für eine grundsätzliche Kritik an dieser Einstufung steht das Plädoyer des Historikers Rainer Zitelmann zugunsten eines „wertfreien“ Begriffs von Modernität, der besagt, dass moderne Visionen nicht „human orientiert und keineswegs einem demokratischen Gesellschaftsverständnis verpflichtet" sein müssen. ${ }^{212}$ Zitelmann erfasst die Moderne vor allem mit den Kriterien technische Entwicklung, Chancengleichheit, Wohlstand und Sozialstaatlichkeit und attestiert dem Nationalsozialismus in diesen Bereichen Progressivität. ${ }^{213}$ Durch die Beschränkung auf rein „empirische Befunde“ und die eklektizistische Auswahl von Indikatoren entwirft er ein Bild von Modernität, das sich auf die Modernisierungsleistungen vor allem im industriegesellschaftlichen und sozialpolitischen $\mathrm{Be}-$ reich stützt. ${ }^{214} \mathrm{Ganz}$ abgesehen von der Tatsache, dass die sozioökonomische Modernisierungsleistung, wie an der Motorisierungspolitik gezeigt wurde, oftmals bescheiden war, liegt das Problem dieses Ansatzes darin, dass er den ideologischen und insbesondere rassistischen Wesenskern, der den Modernisierungsmaßnahmen anhaftet, isoliert. Ein wichtiges Kennzeichen der NS-Motorisierungspolitik war aber gerade das Bestreben, rassistisches Denken durchzusetzen und die Technik als deutsche Technik ideologisch aufzuladen. Um dem spezifisch „Nationalsozialistischen“ der Modernisierungsmaßnahmen im „Dritten Reich“ Rechnung zu tragen, charakterisieren Forscher die nationalsozialistische Politik beispielsweise als "reaktionären Modernismus“ (Jeffrey Herf), als „nationalsozialistische Moderne“ 215 oder als „autochthone Modernität“216.

Misst man der Frage nach der Modernität des NS-Regimes jedoch eine Schlüsselrolle für die historische Einordnung des „Dritten Reiches“ in die deutsche Geschichte zu, würde man die Deutungsmacht dieses Analyseinstruments überbewerten. Vorbehalte sind angezeigt: Veränderungen in Richtung moderne Indus-

210 Herf: Reactionary Modernism, S. 195.

211 Ebenda, S. 224

212 Vgl. Zitelmann: Die totalitäre Seite der Moderne, S. 19; ders.: Selbstverständnis, S. 378.

213 Vgl. Zitelmann: Die totalitäre Seite der Moderne, S. $16 \mathrm{f}$.

214 Zur Kritik an Zitelmanns Begriff der Moderne: Roth: Verklärung des Abgrunds, S. 7-11; Weißbecker: Rezension, S. 366.

215 Grode: Nationalsozialistische Moderne.

216 Graeb-Könnecker: Autochthone Modernität. Der Autor führte die Bezeichnung als Kennzeichen für die nationalsozialistische Literaturförderung ein. Er versteht darunter die „Art und Weise, wie der Nationalsozialismus die moderne Zivilisation kulturell überformen wollte, um deren vermeintlich gefährliche Begleiterscheinungen (einschließlich ihrer Träger) ,auszumerzen' [...]“; ebenda, S. 29. In der vorgenommenen Deutung ist der Ausdruck auf den Nationalsozialismus plausibel anwendbar, doch ist eine derartige Interpretation nicht zwingend aus der Etymologie des Begriffs „autochthon“ (griechisch.: aus dem Lande selbst, eingesessen) abzuleiten. 
triegesellschaft unternahm auch die sozialistische Sowjetunion, wie die Parole "Sowjetmacht plus Elektrifizierung" aus ihrer Gründungsphase zeigt. Die Technik übte eine regimeübergreifende Faszination aus und wurde auch im Stalinismus als Herrschaftsmittel genutzt. ${ }^{217}$ Das allein kann jedoch nicht als stichhaltiges Argument dafür gelten, die beiden Systeme Nationalsozialismus und Kommunismus unter dem Begriff „Modernisierungsdiktatur“ zu subsumieren, wie es Rainer Zitelmann vorschlägt. ${ }^{218}$ Auch Jürgen Kocka diskutiert in Bezug auf die DDR, den Nationalsozialimus und den Stalinismus den Begriff "moderne Dikaturen“ als übergreifende Klassifizierung, um die Gemeinsamkeiten und Zusammenhänge des 20. Jahrhunderts herauszustellen. Er räumt dem Begriff allerdings geringe Aussagekraft ein, wenn es um die Charakterisierung der einzelnen Systeme geht. ${ }^{219}$ In der Tat setzen solche Klassifizierungen Schwerpunkte, die wesentliche Charakteristika und Systemziele des Nationalsozialismus unbenannt lassen: Das Streben nach totalitärer Herrschaft, die Volksgemeinschaftsideologie, die Systemgrundlagen Antisemitismus und Antibolschewismus sowie die Mobilisierung der Technik für die Kriegsführung. Außerdem wird ausgeblendet, und dies spricht ebenfalls gegen den Begriff Modernisierungsdiktatur, dass Hitler die Lösung der sozialen Frage nicht in erster Linie vom Erfolg der industriellen Modernisierung abhängig machte, sondern an rassenimperialistische Ziele knüpfte. Hitlers Obsession vom „Lebensraum im Osten“, dessen Eroberung die Grundlagen für die Erhaltung der arischen Rasse sichern sollte, war wesentlich stärker als das Bestreben, moderne wirtschaftspolitische Lösungsmodelle in Richtung Frieden und Wohlstand im eigenen Land zu verwirklichen. 220

217 Die Spezifika der sowjetischen Technikentwicklung lagen in der Ansammlung technischen Wissens zur Herrschaftsstabilisierung der politischen Klasse, Popularisierung von Technik und Einbettung der Technik in den Bezugsrahmen der Produktions- und Eigentumsverhältnisse; vgl. Städtke: Wandel im Technikbewußtsein, S. $176 \mathrm{f}$.

218 Vgl. Zitelmann: Historiographische Vergangenheitsbewältigung und Modernisierungstheorie, S. 129.

219 Kocka: Die DDR - eine moderne Diktatur?, S. 544 f. Dass der Begriff „modern“ nicht als Schlüsselbegriff zur Gesamtdeutung der NS-Herrschaft taugt, macht auch Michael Prinz deutlich; vgl. ders.: Nachwort: Einige Bemerkungen zur neueren Debatte über Modernisierung und Nationalsozialismus, S. 349.

220 Die Formel basierte auf der irrigen Annahme, ein Staat würde „Lebensraum“ benötigen, um eine prosperierende Wirtschaft zu erhalten; vgl. Overy: War and Economy in the Third Reich, S. 34. 